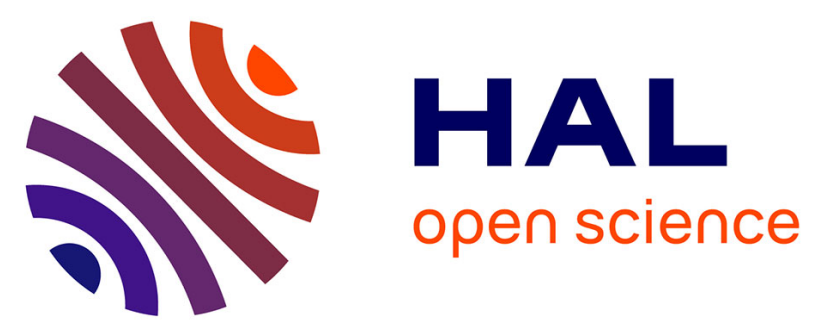

\title{
Asthenosphere and lithosphere structure controls on early onset oceanic crust production in the southern South Atlantic
}

\author{
Chandra Taposeea, John Armitage, Jenny Collier
}

\section{To cite this version:}

Chandra Taposeea, John Armitage, Jenny Collier. Asthenosphere and lithosphere structure controls on early onset oceanic crust production in the southern South Atlantic. Tectonophysics, 2017, 716, pp.4-20. 10.1016/j.tecto.2016.06.026 . insu-02920375

\section{HAL Id: insu-02920375}

\section{https://hal-insu.archives-ouvertes.fr/insu-02920375}

Submitted on 29 Mar 2021

HAL is a multi-disciplinary open access archive for the deposit and dissemination of scientific research documents, whether they are published or not. The documents may come from teaching and research institutions in France or abroad, or from public or private research centers.
L'archive ouverte pluridisciplinaire HAL, est destinée au dépôt et à la diffusion de documents scientifiques de niveau recherche, publiés ou non, émanant des établissements d'enseignement et de recherche français ou étrangers, des laboratoires publics ou privés. 


\title{
Asthenosphere and lithosphere structure controls on early onset oceanic crust production in the southern South Atlantic
}

\author{
Chandra A. Taposeea ${ }^{\mathrm{a}}$, John J. Armitage ${ }^{\mathrm{b}}$, Jenny S. Collier ${ }^{\mathrm{a}}$ \\ ${ }^{a}$ Department of Earth Science and Engineering, Imperial College London, London, UK \\ ${ }^{b}$ Dynamique des Fluides Géologiques, Institut de Physique du Globe de Paris, Paris, France
}

\begin{abstract}
The southern South Atlantic has often been considered a classic example of continental break-up in the presence of a starting mantle plume. Evidence for a mantle plume includes the Paranà-Etendeka continental flood basalts, which are associated with the Rio Grande Rise and Walvis Ridge, and the wide-spread presence of seaward dipping reflectors and high-velocity lower-crustal bodies along the conjugate margins. Observations from seaward dipping reflector distributions suggested that lithospheric segmentation played a major role in the pattern of volcanism during break-up in this region, and consequent numerical modelling was used to test this. We tested this hypothesis ourselves by measuring the thickness of the earliest oceanic crust generated. This was done through the use of 37 measurements of initial oceanic crustal thickness from wide-angle and multichannel seismic profiles collected along the conjugate margins. These measurements show that at $450 \mathrm{~km}$ south of the Paranà-Etendeka flood basalts the oceanic crust is thicker than the global average at $11.7 \mathrm{~km}$. Farther south the oceanic crust thins, reaching $6.1 \mathrm{~km}$ at a distance of $2300 \mathrm{~km}$ along-strike. Overall, the along-strike trend of oceanic crustal thickness is linear with a regression coefficient of 0.7 and little indication of segmentation. From numerical models representing extension of the lithosphere, we find that observed melt volumes are matched with the presence of a hot layer. If we assume this region of hot mantle has a thickness of $100 \mathrm{~km}$, its excess temperature relative to the asthenosphere has to decrease from 200 to $50^{\circ} \mathrm{C}$, north to south. This decrease in temperature, also seen in published thermobarometry results, suggests that temperature was the primary control of volcanism during the opening of the southern South Atlantic.
\end{abstract}

Keywords: South Atlantic volcanic margins, rifting, volcanic passive margin, melt generation, 


\section{Introduction}

Rifting and magmatism are fundamental geological processes that shape the surface of our planet. A relationship between the two is acknowledged, but its precise nature is still not fully understood. White and McKenzie (1989) were among the first to observe a variability in the volume of volcanism during continental break-up world-wide. From a simple 1-D model of lithosphere extension, they concluded that initial lithosphere thickness had little influence on this variability. As a result, mantle temperature was considered as the most influential control on volcanism and the source of increased temperature was suggested to be mantle plumes (White and McKenzie, 1989; White and McKenzie, 1995; Storey, 1995). According to this model, a starting mantle plume impinges the rheological barrier of the lithosphere-asthenosphere boundary, causing its head to flatten and spread into a disk with a diameter of 2000-2500 km (Griffiths and Campbell, 1990, 1991). It is assumed that the highest temperatures are found at the plume axis, with the hot conduit of material supplying this central area, and a reduction in temperature towards the fringes of the plume head (Campbell, 2007). In the North Atlantic, the spread of the mantle plume head is represented by the volcanic passive margins, seen north and south of the Greenland-Iceland-Faeroe aseismic ridges (White and McKenzie, 1989), with a systematic reduction in volcanism along-strike (Holbrook et al., 2001; Collier et al., 2009). Later workers proposed more complicated shapes than the classic "mushroom head" geometry (Houseman, 1990), and that sublithospheric bathymetry, forming an 'upside-down drainage pattern', can have a profound effect on the lateral flow of plume material (Sleep, 1996, 2006).

The validity of temperature as the main control over the degree of volcanism has been questioned by many authors. This work suggests that volcanism during break-up can be strongly influenced by other factors. Previous rift history, initial lithosphere thickness, and possibly even sedimentation, can alter the melting characteristics during margin formation (e.g. Hopper et al., 1992; Lizarralde et al., 2007; Bialas and Buck, 2009; Minshull et al., 2008; Armitage et al., 2010; Buiter and Torsvik, 2014; Fromm et al., 2015). Two contrasting examples are found in the North Atlantic and north-west Indian Ocean pertaining to previous rift history and initial lithosphere thickness. In the North Atlantic, extension before rifting caused a focused 
upwelling, enhancing melt generation. If this previous extension had not occurred, the thermal anomaly would have been held beneath a $125 \mathrm{~km}$ thick lithosphere and not produced ocean crust $17 \mathrm{~km}$ thick (Armitage et al., 2010). In opposition to this, in the Indian Ocean, a previous extension event had the opposite effect, causing the mantle thermal anomaly to exhaust with reduced melt generation represented by ocean crust only $5.2 \mathrm{~km}$ thick (Armitage et al., 2010). As an alternative to the "mantle plume-volcanic margin" association, lithospheric structure can therefore be considered a major factor.

In the South Atlantic, the association between mantle plumes and volcanic margins has also been challenged. Unlike in the North Atlantic, no systematic increase towards the starting plume was observed within the extent and volumes of seaward dipping reflectors (SDRs) (Franke et al., 2007). Instead it was suggested that the lithospheric segment boundaries act as rift-propagation barriers to convecting asthenospheric mantle material, resulting in enhancing and focusing volcanic activity south of these zones (Koopmann et al., 2014a). The increased melting resulted in increased SDR thicknesses and volumes (Franke et al., 2007; Koopmann et al., 2014a,b, Fig. S1). In numerical models, a lateral pressure gradient between sequentially opening segments causes a rift-parallel flow, with consequent elevation in temperature at segment boundaries. The modelling results show increased decompression melting relative to the interior of the segments (Koopmann et al., 2014a). Thus, segmentation is suggested to be an influential control of volcanism in this region.

Here we investigate the primary cause of along-strike variation of volcanism in the South Atlantic by compiling measurements of initial oceanic crustal thickness and testing the influence of temperature and segmentation. Initial oceanic crust provides an independent test of melt volumes previously inferred from syn-rift magmatism, consisting of SDRs and high-velocity lower-crustal intrusions (underplating). The ocean crust thickness represents a 'snapshot' of the asthenosphere conditions immediately post break-up, and can hence be used as a proxy for temperature. To test the primary cause of along-strike variation, we first map the thickness of early onset oceanic crust, and then match these observations to numerical model predictions of volcanism to explore the controls on magmatism within this region. 


\section{Geological Setting}

The break-up of West Gondwana during the Cretaceous to form the South Atlantic (Fig. 1) is commonly associated with the arrival of the Tristan Plume (White and McKenzie, 1989; O'Connor and Duncan, 1990; Renne et al., 1992; Campbell, 2007). The region is often regarded as a classic example of the association between continental break-up with onshore flood basalt provinces, volcanic aseismic ridges and an active volcanic island. The modern-day volcanic island of Tristan da Cunha is spatially and temporally linked via the Rio Grande Rise and Walvis Ridge to the Paranà-Etendeka traps in Brazil and Namibia respectively (Fig. 1a and 2a). The continental margins also display voluminous SDRs and high-velocity lower-continental crustal bodies (Hinz, 1981; Hinz et al., 1988; Gladczenko et al., 1998; Bauer et al., 2000; Franke et al., 2007; Schnabel et al., 2008; Hirsch et al., 2009; Becker et al., 2014).

There are however several departures from the classic starting plume model. Among them is the asymmetry between the Rio Grande Rise and Walvis Ridge, which has been explained by plume drift from the mid-ocean ridge to the African plate around $80 \mathrm{Ma}$ (e.g. O'Connor and Duncan, 1990). This stopped the 'feed' to the Rio Grande Rise, causing the aseismic ridge to terminate production on the South American plate (White and McKenzie, 1989; O'Connor and Duncan, 1990). The Walvis Ridge continued to form, and is traced to the volcano still active today on the Tristan da Cunha island (White and McKenzie, 1989; O'Connor and Duncan, 1990; O'Connor et al., 2012). An additional observed asymmetry is between the volumes of continental flood basalts, where the Paraná traps are significantly larger than the Etendeka traps, with areas of 1.5 million $\mathrm{km}^{2}$ (Courtillot et al., 1999; Peate, 1997) and 80,000 km² (Erlank et al., 1984) respectively. It has been suggested that the disparity between the Paraná-Etendeka traps could be the result of the topographical profile of the base of the lithosphere, causing an asymmetry in ponded plume material (Fromm et al., 2015; Sleep, 2006). The margin likewise has an asymmetric distribution in volcanism from north to south. South of the Rio Grande Rise and Walvis Ridge, the conjugate margins are volcanic with an abundance of SDRs. North of the Ridges, the conjugate margins are magma-poor and lack SDRs (Contrucci et al., 2004; Aslanian et al., 2009; Reston, 2010). This does not fit with the classic plume model, where the plume head would flatten with an axisymmetric geometry, and the presence of volcanism would be expected both north and south of the Rio Grande Rise and Walvis Ridge. 
The duration of the continental flood basalts is debated. From ${ }^{39} \mathrm{Ar} /{ }^{40} \mathrm{Ar}$ dating and paleomagnetic results, Renne et al. (1992) concluded that the eruption of the Paranà occurred at $133 \pm 1 \mathrm{Ma}$ in a time frame of less than a million years, in agreement with Bellieni et al. (1983) and Hawkesworth et al. (1992). However, it is believed these previous samples did not represent the province as a whole (Peate et al., 1992). Turner et al. (1994) showed by using laser spot Ar-Ar analyses evidence of the eruption lasting for $\sim 10 \mathrm{Myr}$, between $137 \mathrm{Ma}$ and $127 \mathrm{Ma}$ (Turner et al., 1994; Stewart et al., 1996). From recent magnetostratigraphy studies for the Etendeka portion of the large igneous province, the Tristan Plume is suggested to be already present by at least magnetic isochron M15n (Dodd et al., 2015), dated 135.96 Ma by Gee and Kent (2007).

The South Atlantic opened in a south to north unzipping fashion, with break-up happening in stages. Moulin et al. (2010) summarised the break-up by sub-plate, with five in our study area, the São Francisco, Santos, Rio de la Plata, Argentina, and Salado blocks, where the movement is fixed relative to the African plate. The sub-plates movements are timed according to sea floor magnetic isochrons M7, M4, M2 and M0 (127.23 Ma, 126.57 Ma, 124.05 Ma and 120.6 Ma respectively, locations in Fig. 2). Towards the south of our study area, there is evidence the Salado and Argentina sub-plates had started to move westward relative to the African plate prior to magnetic isochron M7. Between M7 and M4, the Rio de la Plata sub-plate moved westward, allowing the opening of the northern part of our study area. Following M2, the Rio de la Plata, Salado and Argentina sub-plates moved as one, and movement of the Santos plate also commenced. North of the Rio Grande Fracture Zone the timing of the Atlantic initiation is less well constrained as it occurred within the Cretaceous Magnetic Quiet Zone (CMQZ), 12183Ma (Gee and Kent, 2007). Compared to the ages of the Paranà-Etendeka continental flood basalts, the timing of the first magnetic isochrons (M4 and M7) recognised on the conjugate margins in the south of our study area suggests the presence of an elevated mantle temperature prior to break-up.

Like most continental margins, the southern South Atlantic has clear segmentation present along-strike. The continents of South America and Africa contain areas of structural weakness, which are inferred to have influenced continental break-up and initial sea floor spreading (Rosendahl, 1987; Clemson et al., 1997, 1999; Jungslager, 1999; Franke et al., 2007). Franke et al. (2007) and Koopmann et al. (2014b) presented four major transfer zones in the South American and African margins respectively, linked to the Proterozoic mobile fold belts found 
on adjacent continents. Seen from observations of increasing volumes of SDRs towards segment boundaries (Fig. S1), they proposed that increased magmatism towards these zones is due to increased decompression melting. Franke et al. (2007) and Koopmann et al. (2014b) both suggested that segmentation has a high influence on magmatism in the South Atlantic region, seeing no systematic increase in SDR volumes towards the Rio Grande Rise and Walvis Ridge. 


\section{Methodology}

\subsection{Tectonic framework: along-strike variability}

We analysed the spatial variation of the thickness of initial oceanic crust for our study area. In order to compare the data from conjugate margins, we assessed the current plate reconstruction models. We investigated in detail the models of Torsvik et al. (2009), Moulin et al. (2010) and Heine et al. (2013). Using the GPlates software package, we combined these reconstructions with the most-recent satellite gravity and magnetic data sets (Sandwell et al., 2013; Maus et al., 2007). From the reconstructed gravity and magnetic data, we concluded that within our study area the magnetic isochrons correlated best with the Moulin et al. (2010) plate reconstruction (Fig. 1). Using this framework, we then measured distance along-strike relative to the reconstructed locations for the Rio Grande Rise and Walvis Ridge respectively (shown by the two ' + ' symbols in Fig. 1).

To map the lithospheric segment boundaries, we started with those identified by Franke et al. (2007) on the South American margin and Koopmann et al. (2014b) on the African margin, both largely defined by continental structural variations (Fig. S1). We then independently picked the locations of the major fracture zones from the satellite gravity and magnetic data sets (Sandwell et al., 2013; Maus et al., 2009) and tested for conjugate symmetry using GPlates, making small refinements to the boundary locations. Within our study area, the Moulin et al. (2010) model has five sub-plates forming part of the South American continent (São Francisco, Santos, Rio de la Plata, Argentina, and Salado blocks, Fig. 2), with a single sub-plate forming part of Africa (Austral block). The sub-plate boundaries on the South American margins are used to define our 'first-order segments', numbered 1 - 4. These sub-plates boundaries also coincide with major fracture zones (defined as having a minimum offset of $50 \mathrm{~km}$ at the modern ridge axis), craton locations (Gubanov and Mooney, 2009), and other onshore zones of weakness (Moulin et al., 2010; Heine et al., 2013). In addition, we recognised 'second-order segments' that show clear fracture zone traces on conjugate sides, numbered alphabetically (e.g. Segments $3 b$ \& 3a). 
To explore the thermal structure of our study area immediately post break-up, the thickness of the first oceanic crust generated was used as a proxy for melt production. To measure this thickness, we compiled wide-angle and multichannel seismic reflection (MCS) profile data within our study area. In total we sourced 37 profiles, consisting of 7 wide-angle profiles and 30 MCS profiles. The wide-angle profiles are distributed across both the conjugate margins and along-strike, with 4 on the African side (AF1-4) and 3 on the South American side (SA1-3; Bauer et al., 2000; Schinkel, 2006; Hirsch et al., 2009; Becker et al., 2014; Schnabel et al., 2008; see Table 1). The MCS data was limited to the South American margin, as we required that these seismic lines imaged both the top basement and the Moho. We used ten MCS published sections from Hinz et al. (1999) and Franke et al. (2007, 2010) (Fig. 4). Six additional MCS profiles (Fig. 4 and S7) were from Winterbourne et al. (2014), which originate from a mixture of unpublished seismic industry data and published seismic data. Finally, we used fourteen lines of unpublished, industry, high quality seismic reflection survey lines from the BasinSPAN acquisition project of ION Geophysical.

In order to obtain a consistent indication of melt production along-strike, we measured the thickness of oceanic crust on each profile using a criterion known as Landward Limit of Oceanic Crust (LaLOC). The LaLOC is defined as the 'boundary which delimits relatively homogeneous oceanic crust ocean-ward from either extended continental crust or exhumed continental lithospheric mantle landward or Seaward Dipping Reflectors (SDRs), where an interpretation of the Moho and/or the extent of continental crust is not possible' (Heine et al., 2013).

A combination of magnetic and seismic characteristics was used to locate the LaLOC. Firstly, in our study area, magnetic isochrons M2 and M0 (Fig. 2) are generally recognised as sea floorspreading being underway (Moulin et al., 2010). Secondly, the SDRs, which are relatively wellimaged on all lines, are normally located landward of the oldest oceanic crust. On wide-angle profiles, high $\mathrm{P}$-wave velocity bodies in the lower crust (underplating), typically with values $>7.0 \mathrm{~km} \mathrm{~s}^{-1}$ (Becker et al., 2014; Trumbull et al., 2015), are taken to indicate the presence of highly intruded stretched continental or transitional crust. Hence, the LaLOC must be seaward of all underplating observed on wide-angle seismic profiles. As an additional check, we extracted depth- $\mathrm{V}_{p}$ profiles from the wide-angle models and tested for the presence of oceanic, stretched 
transitional or continental crust. We used the $\mathrm{V}_{p}$ limits from White et al. (1992) to define mature oceanic crust. Using this extra criterion, the LaLOC can coincide with overlying SDRs when supported by evidence. Finally, we considered the reflectivity character, with true ocean crust typically being devoid of internal reflectivity and showing a recognisable 'bumpy surface', as an indication of the presence of pillow lavas (Fig. S3-S6).

An example of our identification of the LaLOC location is given for wide-angle profile AF2 in Fig. 3. Underplating for this profile is characterised with a $\mathrm{V}_{p}>7.15 \mathrm{~km} \mathrm{~s}^{-1}$, and we present 3 possible LaLOC locations seaward of this velocity body, representing a degree of uncertainty for initial oceanic crustal thicknesses (Fig. 3a). They are found near magnetic isochron M4 (Moulin et al., 2010), and as this coincides with SDRs, we tested the depth- $\mathrm{V}_{p}$ profiles for the seismic velocity boundaries of mature oceanic crust (White et al., 1992). This allowed us to locate the initial production point for oceanic crust (Fig. 3b) and verify we are not in transitional crust. This process was followed for all of the wide-angle profile (Fig. S2).

In order to ensure consistency between oceanic crust thickness measurements at the LaLOC made from MCS profiles, all measurements were performed on time sections (Fig. 4). These were then converted to distance using a mean $V_{p}$ value for oceanic crust of $6.7 \mathrm{~km} \mathrm{~s}^{-1}$ (White et al., 1992). White et al. (1992) found $90 \%$ of the ocean crust velocity estimates fall within a range of $6.4-7.0 \mathrm{~km} \mathrm{~s}^{-1}$, representing a $\pm 0.45 \mathrm{~km}$ error for a crustal thickness of $10 \mathrm{~km}$.

The majority of the available seismic profiles stop soon after the LaLOC as they were collected to study the continent-ocean transition. The ION Geophysical lines however extend up to $\sim 660 \mathrm{~km}$ into oceanic crust. This allowed us to measure the age trend of oceanic crustal production in the north of our study area (Fig. 2). To map the oceanic crust thickness to sea floor age, we used the Gee and Kent (2007) time scale and Moulin et al. (2010) magnetic isochrons for our study area. This allowed for distance along the profile to be converted to age, and subsequently we averaged the thickness into $1.5 \mathrm{Myr}$ bins.

\subsection{Numerical Modelling}

To better our understanding of our study area's initial break-up conditions, we use a 2D viscous model of the upper mantle to simulate continental break-up. The numerical model, 
based on CitCom (Moresi et al., 1996), is a finite element code designed to solve incompressible thermochemical convection problems relevant to the Earth's mantle. It is a fluid dynamic model capable of handling large viscosity contrasts where Stokes equations are solved in a fixed Cartesian domain (Moresi et al., 1996). This model was modified by Nielsen and Hopper (2004) to include melt production due to decompression melting. Equations are solved in $2 \mathrm{D}$, using the Boussinesq approximation with the understanding that (1) density variations are sufficiently small that they only affect gravitational forces and (2) effect on mantle density due to mass transfer during melting is small (Cordery and Morgan, 1993). The model is set up with a non-Newtonian dislocation creep as described in Appendix A.

The model space is represented by a domain $2,800 \mathrm{~km}$ wide, $700 \mathrm{~km}$ deep, with $256 \times 256$ elements (Fig. 5). An increased resolution of 512x512 elements was tested by Nielsen and Hopper (2004), however the differences in predicted crustal thicknesses were in the order of a few percent, so the less computationally expensive resolution was used. The initial lithosphere is assumed to be melt depleted and therefore compositionally buoyant relative to the asthenosphere. A hot layer is introduced, simulating the presence of an impacted plume head at the lithosphere/asthenosphere boundary (Fig. 5). Extension is imposed by a surface velocity boundary condition at a fixed spreading rate, driving the lithosphere apart laterally (see for example Nielsen and Hopper, 2004; Armitage et al., 2010). As the lithosphere extends and thins, material moves upwards leading to decompression melting.Crustal thickness $\left(\mathrm{h}_{c}\right)$ is calculated with the assumption that all melt is focused and accreted at the ridge axis using

$$
h_{c}=\frac{2}{u_{z}}\left(\frac{\rho_{m}}{\rho_{l}}\right) \iint_{m e l t} \dot{m} d x d z
$$

where $\mathrm{u}_{z}$ is the mantle flow in the vertical direction, $\rho_{m}$ is the density of the lithospheric mantle, $\rho_{l}$ the melt density and $\dot{m}$ is the melt production rate (Ito et al., 1996; Nielsen and Hopper, 2004). Further details of the model can be found in Appendix A. The sides of the model domain are reflective boundaries, with no lateral flow of heat or material across them (Fig. S9). This is assumed not to affect melt thickness results, as the reflective boundaries (example Fig. S9) are considered to be far enough from the centre of extension (Nielsen and Hopper, 2004). 


\subsubsection{Understanding model sensitivity}

To understand the sensitivities of the model, we started with a simple simulation with a model asthenosphere temperature of $1300^{\circ} \mathrm{C}$, spreading velocity of $12 \mathrm{~mm} \mathrm{yr}^{-1}$, and an initial lithosphere thickness of $125 \mathrm{~km}$. In some of the models, we introduced a $100 \mathrm{~km}$ thick hot layer as the impacted plume head at the lithosphere/asthenosphere boundary. Three model runs are first demonstrated with no hot layer, a $100{ }^{\circ} \mathrm{C}$ hot layer, and a $200{ }^{\circ} \mathrm{C}$ hot layer in excess of the model asthenosphere temperature (Fig. 6a). Three main stages of melt production can be seen for the model as the lithosphere thins and is finally broken (Fig. 6a): pre-rift, syn-rift and post-rift. The pre-rift stage is where there is little magmatism and syn-rift is where there is a magmatism peak. There is a clear increase in output magmatism as the hot layer temperature increases, with $\sim 3$ times as much for the $200^{\circ} \mathrm{C}$ hot layer relative to no hot layer (Fig. 6a). Following the peak magmatism in the syn-rift phase, the post-rift phase represents a shift towards steady-state sea floor spreading (Fig. 6a). The first instance of ocean crust will occur along this decreasing trend, and can be matched to observations of the seismic data.

The evolution of the numerical model from pre-rift to post-rift is a function of the hot layer temperature (Fig. 6a). The hottest model, with a thermal anomaly $200{ }^{\circ} \mathrm{C}$ hotter than the model asthenosphere temperature, displays peak melt production $\sim 3 \mathrm{Myr}$ earlier than the equivalent model that has a $100{ }^{\circ} \mathrm{C}$ hot thermal anomaly (Fig. 6a). For model runs without a hot layer present, there is no syn-rift peak in magmatism for any of the models. Increasing the model asthenosphere temperature reduces the model duration for the pre-rift phase, and increases the steady-state oceanic crustal thickness (Fig. 6b). Varying the spreading rate likewise affects the duration of pre and syn-rift phases, and ultimately when the post-rift phase is achieved (Fig. 6c). Doubling the rate of extension reduces the pre-rift duration by at least half. A faster spreading rate creates a larger pulse of decompression melting during the syn-rift phase when a hot layer is present, and a slower spreading rate will significantly increase the duration of the pre-rift phase (Fig. 6c). This is because a faster rate of extension causes a greater amount of material to be fluxed through the zone of partial melting (Fig. S9b and c).

To explore how the model that includes a thermal anomaly (e.g. Fig. 6a) evolves for a range of hot layer temperatures $\left(50\right.$ to $200^{\circ} \mathrm{C}$ ) and initial lithosphere thicknesses (100 to $140 \mathrm{~km}$ ), we plotted the melt thickness at three model times, 10, 15 and $20 \mathrm{Myr}$ (Fig. 7). If the hot 
layer temperature is $50{ }^{\circ} \mathrm{C}$, then the melt thickness is always less than $10 \mathrm{~km}$. Increasing this temperature increases the volume of melt, but the time of maximum melt production is a function of the hot layer temperature (Fig. 6a) and also of the initial lithosphere thickness (Fig. 7). For models with an initial lithosphere thickness of $140 \mathrm{~km}$ and hot layer temperatures $\geq 100{ }^{\circ} \mathrm{C}$, at $10 \mathrm{Myr}$ melting is reduced. However, if the initial lithosphere thickness is $100 \mathrm{~km}$, then by $20 \mathrm{Myr}$ the thermal anomaly is exhausted (Fig. 7). This demonstrates the importance for understanding the timing of initial oceanic crustal thickness, and to constrain the initial lithosphere thickness from the available geophysical evidence.

\subsubsection{Initial lithosphere thickness and rate of extension}

To reduce the number of unknowns, we assumed that the initial lithospheric thickness and extension rate could be estimated from geophysical observations. The initial lithosphere thickness is estimated from the point at which the available seismic imaging suggests un-stretched continental crust to be present. To estimate the lithosphere thickness at this point, we used the tomographic models of Priestley and McKenzie (2006) for the South American side, and Fishwick and Bastow (2011) for the African side (Table 2). We used the Fishwick and Bastow (2011) model for the African side for several reasons. The increased number and distribution of seismic station allows more ray coverage in this region, with Fishwick and Bastow (2011) having a specific focus on Southern Africa (Fishwick, 2010). Although it uses the empirical parameterisations from the Priestley and McKenzie (2006) model, the latter has an automated code and the former employs a semi-automated code, using a manual comparison of multiple inversions for each path (Fishwick, 2010). Through the use of a model based on petrology, mineral physics, gravity anomaly and heat flow, Fernandez et al. (2010) gave an estimate of lithosphere thickness in the Namibia region. Given the different methods and different resolution, the lithosphere thickness model agrees better with the model from Fishwick and Bastow (2011), and therefore consider the latter more reliable in this area (Fig. S10). In order to address the observational uncertainties and differences seen in the two models (Fig. S10), we included simulations with varying initial lithosphere thicknesses (Table 2) to ensure the robustness of our excess model asthenosphere temperature predictions.

The reliability of using present day estimates of lithosphere thickness as a proxy for prebreak-up lithosphere thickness was explored by McKenzie et al. (2015). They presented a map 
of lithospheric thickness for Pangea, using a reconstruction of continental plates within the Permian, assuming the lithosphere moves with overlying continents. They found a continuity of thicker and thinner lithosphere, for example at the Pan-African orogenic zones and cratons. If lithosphere deformation had occurred since the Permian, there should be no reason for them to fit within a reconstruction of Pangea. We tested this using the rotation poles from Moulin et al. (2010) with the lithospheric grid from Priestley and McKenzie (2006), the latter covering both sides, and likewise found that there was a good correlation between the conjugate sides in terms of lithospheric thickness (Fig. 1b). Hence, we assumed present day values could be used as a parameter for initial lithosphere thickness within the model.

Heine et al. (2013) summarised sea floor spreading rates through the South Atlantic breakup from $126.57 \mathrm{Ma}$ (magnetic isochron M4) to $100 \mathrm{Ma}$. These range from 10 to $18 \mathrm{~mm} \mathrm{yr}^{-1}$, increasing in speed towards the south (Table 2). In our modelling, we assumed the pre-break-up extension rates matched those seen during early sea floor spreading. The primary value we used is $12 \mathrm{mmyr}^{-1}$, as this applied to Segments 3b, 3a and 2 until 126.57 Ma (M4). Following this, the rate increased to $35 \mathrm{~mm} \mathrm{yr}^{-1}$ for the period $126.57-120.6 \mathrm{Ma}$, and subsequently increased to $58 \mathrm{~mm} \mathrm{yr}^{-1}$ (Heine et al., 2013). Moulin et al. (2010) has similar rates for these times, at $38 \mathrm{~mm} \mathrm{yr}^{-1}$ and $50 \mathrm{~mm} \mathrm{yr}^{-1}$ respectively, but does not suggest a rate prior to M4. Heine et al. (2013) found the spreading rate of $18 \mathrm{~mm} \mathrm{yr}^{-1}$ in the extreme south of our study area, covering Segments $1 \mathrm{~b}$ and 1a.

\subsubsection{Model asthenosphere temperature structure}

The choice of the model asthenosphere temperature range is crucial, with a change in temperature of $12.5^{\circ} \mathrm{C}$ accounting for melt thickness changes by up to $1 \mathrm{~km}$ (McKenzie et al., 2005). Herzberg et al. (2007) found that mid-ocean ridge basalts (MORBs) with a 10-13\% MgO content would have potential temperature range of $1280-1400^{\circ} \mathrm{C}$. This should cover the feasible range for model asthenosphere temperature in the South Atlantic. To refine this range of temperatures, we made use of the long-offset ION Geophysical lines found in the north-west region of our study area. These profiles record the reduction in oceanic crustal thickness away from the passive margin and towards steady-state. We can therefore compare this crustal thickness farthest from the margin with that generated by the model at a steady-state. 
A hot layer with a temperature in excess of the model asthenosphere temperature was added to recreate the distal regions of the mantle plume or thermal anomaly (Fig. 5; Armitage et al., 2010). The hot layer can vary in temperature where, classically, temperature is considered the main driver of crustal thickness (White and McKenzie, 1989). In all models, we assumed the hot layer was present below the lithosphere before the onset of extension. The excess temperature of the hot layer closest to the centre of the province can be estimated from the thickness of the basaltic crust from the Rio Grande Rise and Walvis Ridge. The Walvis Ridge thickness is observed between $\sim 26-28 \mathrm{~km}$ from seismic sections (Fromm et al., 2015). When the McKenzie and Bickle (1988) melting model is used, a $200^{\circ} \mathrm{C}$ excess temperature is required to match this thickness (Campbell, 2007). We assumed such an excess temperature for the hot layer with proximity to the Rio Grande Rise and Walvis Ridge and varied it along-strike. We solved for decompression melting at various hot layer temperatures and compared the results to the alongstrike variation in ocean crust thicknesses measured at the LaLOC for the wide-angle profiles (Fig. S2). We used the relative ages of the oceanic crust at the LaLOC location, known from location of magnetic isochrons, to discriminate between results from models with different hot layer temperatures. 
4. Results

\subsection{Observed variation in ocean crustal thicknesses}

When all the initial oceanic crustal thickness measurements were considered (Table 1), there was a clear negative trend with oceanic crust thinning with increasing distance along-strike from the Rio Grande Rise and Walvis Ridge (Fig. 8a). The trend has a gradient of $-2 \times 10^{-3}$ and a correlation coefficient of 0.7 . This translates to a reduction in oceanic crustal thickness of $0.16 \mathrm{~km}$ per $100 \mathrm{~km}$ in a southern direction from the aseismic ridges. On the African margin, we observed a thicker ocean crust towards the Walvis Ridge. The wide-angle seismic profile AF1 has an initial oceanic crustal thickness measuring $11.7 \mathrm{~km}$ at an along-strike distance of $\sim 450 \mathrm{~km}$ (Fig. S2), which reduces to a thickness of $7.0 \mathrm{~km}$ at profile AF4 in the south at an along-strike distance of $\sim 1420 \mathrm{~km}$ (Fig. S2). This trend is very similar on the South American margin, with a maximum thickness of $10.0 \mathrm{~km}$ from the most northern ION Geophysical profile $\sim 260 \mathrm{~km}$ away, to only $6.0 \mathrm{~km}$ in the southern edge of measurements $\sim 2300 \mathrm{~km}$ away.

When the oceanic crustal thickness measurements at the LaLOC location were compared to the segment boundaries (Fig. 8), we did not find any obvious thickening south of the segment boundaries. By using the ION Geophysical long-profiles that extend to a distance of $660 \mathrm{~km}$ offshore, covering an age range of approximately 15 Myr (Fig. 9), we checked if there was a signal in the oceanic crustal thickness as the profiles cross segment boundaries (Fig. 9 and 10). The long-profiles have an overlying trend of a decrease in oceanic crustal thickness with distance from the passive margin and no clear indication of increased decompression melting at the segment boundaries (Fig. 10). From the seismic sections, we could see clear oceanic crust, devoid of internal structure with a bumpy surface, representative of pillow lavas.

We further investigated Lines 1 and 2, both transgressing segment boundaries (Fig. 10). The ocean crust thickness for both of the lines show local thickness variations with an amplitude of $1 \mathrm{~km}$. Oceanic crustal thickness decreases from 10.2 to $6.3 \mathrm{~km}$ along Line 1 (Fig. 10a), and 8.5 to $6.5 \mathrm{~km}$ for Line 2 (Fig. 10b). We did not observe a sharp change in melt production as described by Franke et al. (2007) and Koopmann et al. (2014b), but there is an overall decreasing trend with age. 


\subsection{Results from numerical model}

\subsubsection{Establishing model asthenosphere temperature}

The long offset ION Geophysical data demonstrates the decreasing oceanic crustal thickness with distance from the passive margin (Fig. 10). Having age-assigned the lines according to location, we found for Segments 3b, 3a and 2 that the oceanic crustal thickness trends to 7.2, 6.7 , and $6.6 \mathrm{~km}$ respectively (Fig. 11). This suggests that towards the end of these profiles steady-state oceanic crustal production has been achieved.

Comparing these trends to our model predictions without any thermal hot layer allowed us to conclude that the model asthenosphere temperature was in the range of $1315-1325{ }^{\circ} \mathrm{C}$ (Fig. 11). We saw a higher thickness for Segment 3b due to local thickening of the ocean crust over Line 1 (Fig. 10a), causing an overall increased thickness. However, before this, the thickness was also tending to $1315^{\circ} \mathrm{C}$. Therefore, we used $1315^{\circ} \mathrm{C}$ as our model asthenosphere temperature in all our models.

\subsubsection{Establishing hot layer temperatures}

Having established a model asthenosphere temperature of $1315^{\circ} \mathrm{C}$, we then solved for the excess temperature of the hot layer. For all models, we assumed the hot layer was present below the lithosphere prior to the onset of extension (as demonstrated in Fig. 6a). We estimated the temperature of the hot layer by comparing variations in ocean crustal thicknesses for our wide-angle profiles at the LaLOC location (Fig. 12).

We assumed that the present day continental lithosphere thickness at the margin is representative of the initial configuration (Fig. 1b) and we varied the temperature of the hot layer within the range of 50 to $200{ }^{\circ} \mathrm{C}$. Using a model asthenosphere temperature of $1315^{\circ} \mathrm{C}$ and spreading rates of 12 and $18 \mathrm{~mm} \mathrm{yr}^{-1}$ covering Segments $1-3$, we tested several scenarios. To demonstrate the effect of initial lithosphere thickness and the importance of timing, we ran a model with an initial lithosphere thickness of $125 \mathrm{~km}$ (Fig. 12a). The model was capable of matching all values for the initial oceanic crust in the post-rift stage (ie. Fig. 6a) from wide-angle seismic profiles AF1 to AF4 on the African side of the South Atlantic, but this match required a $20 \mathrm{Myr}$ 
difference in age along the margin (Fig. 12a). With magnetic isochron data from Moulin et al. (2010) and using the Gee and Kent (2007) timescale, we estimated the range in age along the margin for the initial oceanic crust produced. We found a range of ages of $1.0 \mathrm{Myr}$ for the African profiles and 5.7 Myr for the South American profiles.

If we allowed the temperature of the hot layer to vary along-strike, we found that the model with an excess temperature of $200^{\circ} \mathrm{C}$ matched the observations for wide-angle seismic profile AF1 (Fig. 12b) in its post-rift stage. Moving southward along the African margin, models with a reduced excess temperature of 150,75 and $50^{\circ} \mathrm{C}$ and varying initial lithosphere thicknesses were in line with the observed thickness, fitting the first oceanic crustal thickness for profiles AF2, AF3 and AF4 respectively (Fig. 12b). We therefore found that by taking the observed continental lithosphere thickness and changing the hot layer temperature, we could match the thickness of the first oceanic crust within a consecutive time range of $2.5 \mathrm{Myr}$, much closer to the observed range of $1.0 \mathrm{Myr}$. If our assumption of a constant extension rate is correct, then these models also imply that the total duration of rifting in the South Atlantic was of the order of 25 to $30 \mathrm{Myr}$.

Rates of early sea floor spreading along the South American margin vary from $12 \mathrm{~mm} \mathrm{yr}^{-1}$ for profile SA1 in Segment 3a to $18 \mathrm{~mm} \mathrm{yr}^{-1}$ for profiles SA2 and SA3 in Segment 1a and 1b (Table 2). To capture this, we modelled two extension rates along with varying the temperature of the hot layer. Accounting for this difference, we found a set of models that could match the distribution of initial oceanic crustal thickness in the post-rift stage close to the $5.7 \mathrm{Myr}$ age window of the three measurement points (Fig. 12c). A model with an excess temperature of $100{ }^{\circ} \mathrm{C}$ is concurrent with observations for SA1, and moving south, this reduced to $75^{\circ} \mathrm{C}$ for SA3 (Fig. 12c). These fits imply a reduced duration of extension for the most southerly part of the South American margin relative to the more northerly conjugate margins in South America and on the African side. We predict a rift duration of $15 \mathrm{Myr}$ due to the faster rate of extension for profiles SA2 and SA3, compared to 25 to 30 Myr for profiles AF1 - 4 and SA1.

\subsubsection{Results for segment-age trends}

To compliment our results from wide-angle profiles, we used our segment-age trend observations from the long offset ION Geophysical profiles (Fig. 11). The oceanic crustal thickness 
was plotted for each segment binned into 1.5 Myr intervals (Fig. 13). Since this data is from Segments 3b, 3a and 2, we assumed a model spreading rate of $12 \mathrm{~mm} \mathrm{yr}^{-1}$ (Table 2). Although this rate of extension is valid until 126.57 Ma (Heine et al., 2013), once at steady-state, changing the spreading rate produces oceanic crustal thickness within the same range of values (Fig. 6c). Therefore, for simplicity the spreading rate was kept at $12 \mathrm{~mm} \mathrm{yr}^{-1}$. As before, the models have a model asthenosphere temperature of $1315^{\circ} \mathrm{C}$, with varying hot layers and initial lithosphere thickness per segment. The preferred model was determined by calculating a normalised root mean square error (NRMSE).

We compared the post-rift stage of the models with hot layers of 50 to $200^{\circ} \mathrm{C}$ against the trend of reducing oceanic crustal thickness with age for each segment (Fig. 13). We found for Segment $3 \mathrm{~b}$ that a model with a hot layer of $200^{\circ} \mathrm{C}$ provided the best fit to the observations (Fig. 13a). This model implied that extension initiated at 147 Ma. For Segment 3a, the best fit model had a hot layer of $150^{\circ} \mathrm{C}$ where extension was also initiated at $147 \mathrm{Ma}$ (Fig. 13b). Segment 2 was best matched by a model with a hot layer of excess temperature $75^{\circ} \mathrm{C}$, suggesting extension initiated at $141 \mathrm{Ma}$. As for the comparison to the wide-angle data (Fig. 12), these models suggest a similar Late Jurassic age for the initiation of extension in the southern South Atlantic.

The modelling matches to the oceanic crustal thickness from the wide-angle seismic lines (Fig. 12) and the long offset ION Geophysical profiles (Fig. 13) allow for the change in hot layer temperature to be plotted against distance along-strike for both margins (Fig. 14). Here we observe a general temperature decrease trend from a thermal anomaly of $200{ }^{\circ} \mathrm{C}$ in the north to $75^{\circ} \mathrm{C}$ in the south (Fig. 14). A linear fit to all the data points would suggest a reduction of $\sim 40{ }^{\circ} \mathrm{C}$ per $500 \mathrm{~km}$ distance along-strike. Within this general trend, we found evidence, for example within both Segments $3 \mathrm{~b}$ and $3 \mathrm{a}$, for a drop of temperature of $\sim 50^{\circ} \mathrm{C}$ over roughly $100 \mathrm{~km}$ distance. While there is a large degree of uncertainty on these model predictions, these drops in temperature occur within the segments and not at their edges. This may suggest that segment boundaries play only a minor role in the volcanic nature of continental break-up. 


\section{Discussion: Evidence for a mantle plume?}

Franke et al. (2007) and Koopmann et al. (2014b) have suggested lithospheric segmentation as a highly influential factor affecting volcanism in the South Atlantic. They established this from increasing widths and volumes of SDRs towards segment boundaries, and did not take initial oceanic crustal thicknesses into account (Fig. S1). Our study differs from these previous publications on continental break-up in the southern South Atlantic, as it concentrates on post-rift volcanism, where initial production of ocean crust is located, rather than syn-rift volcanism, where SDRs are found (Franke et al., 2007; Koopmann et al., 2014b,a). From our results, we suggest that oceanic crustal thickness is primarily controlled by temperature and initial lithosphere thickness. There is no clear systematic trend for increased magmatism relative to segments boundaries from ocean crust thickness observations and consequent modelling (Figs. 8b, 10, and 14).

In the North Atlantic (Fig. 8a), Collier et al. (2009) presented ocean crust measurements both south and north of the Greenland-Iceland-Faeroe Ridges. The trend for this area was a reduction of $1.67 \mathrm{~km}$ per $100 \mathrm{~km}$ increased distance from the aseismic ridges, a stark difference to the trend seen in the South Atlantic, with a reduction of $0.16 \mathrm{~km}$ per $100 \mathrm{~km}$ (Fig. 8a). In the past, continental break-up in the North and South Atlantic have been regarded similar, with mantle temperature being deduced as the primary factor (e.g. White and McKenzie, 1989). The North Atlantic is considered in line with the classic 'mushroom head' plume model, with an axisymmetric geometry inferred from volcanic margins both north and south of the GreenlandIceland-Faeroe Ridges. This is not seen in the South Atlantic, where volcanic passive margins are found on conjugate margins south of the Rio Grande Rise and Walvis Ridge, but magmapoor passive margins are found to the north (Contrucci et al., 2004; Aslanian et al., 2009; Reston, 2010; Fromm et al., 2015). Additionally, the North Atlantic underwent a pre-thinning extension event prior to break-up, causing enhanced melt generation through focused upwelling (Armitage et al., 2010). This is not seen in our study area, and given the effect of temperature and lithosphere thickness on break-up volcanism modelled here (e.g. Fig. 10), we suggest that the varying trends seen between the North and South Atlantic indicate differing initial break-up conditions, in both initial lithosphere structure and mantle temperature.

Through our simulations, we show a simple 2D model can match initial ocean crust thickness, 
and is sensitive to changes in initial lithosphere thickness, mantle asthenosphere temperatures and hot layer temperatures (Fig. 7 and 14). Our results indicate the presence of a reduction of temperature, both in direction parallel to the margin along-strike and in time. The along-strike decrease can be linked to a reduction in temperature as we move from a mantle plume axis to its fringes (e.g. Campbell, 2007). From modelling the thickness of oceanic crust generated by decompression melting, we estimate that there is a reduction in temperature from $1515^{\circ} \mathrm{C}$ near the Rio Grande Rise and Walvis Ridge (Profile AF1 with a distance of $450 \mathrm{~km}$ ) to $1365-1390^{\circ} \mathrm{C}$ at the edge of the segments in the south (Profile SA3 at a distance of $2300 \mathrm{~km}$ ). This suggests the presence of a mantle plume, or at the very least a thermal anomaly, reaching temperatures of $200{ }^{\circ} \mathrm{C}$ above the model asthenosphere temperature of $1315^{\circ} \mathrm{C}$.

Putirka (2005) calculated the temperature for the Hawaii and Iceland plumes, finding them to be $250 \pm 50^{\circ} \mathrm{C}$ and $165 \pm 60^{\circ} \mathrm{C}$ hotter than asthenosphere temperature, which is within range of our maximum excess temperature of $200^{\circ} \mathrm{C}$. Coupled with a model asthenosphere temperature of $1315{ }^{\circ} \mathrm{C}$, our maximum temperature of $1515^{\circ} \mathrm{C}$ falls in the limits of the maximum potential temperature for the Rio Grande Rise and Walvis Ridge in the northern region of our study area, estimated at $1450-1540{ }^{\circ} \mathrm{C}$ (Gallagher and Hawkesworth, 1994). Furthermore, our results agree with thermobarometry results from Trumbull (2014), where from a compilation of onshore basalts, a north to south decrease in temperatures of $140{ }^{\circ} \mathrm{C}$ from $1520^{\circ} \mathrm{C}$ in the north to $1380^{\circ} \mathrm{C}$ in the south is seen.

With our models, we can also estimate the duration of rifting. We predict a rift duration in the order of 23.5 to $30 \mathrm{Myr}$ for Segments 2 and 3, reduced to $15 \mathrm{Myr}$ for Segment 1. Given that the first magnetic isochrons are roughly $126 \mathrm{Ma}$, this places the onset of extension for our study area to be within the Late Jurassic. Despite the simplifications of the geodynamic model, such an age for the onset of extension is quite reasonable. Several studies have found evidence for the commencement of rifting in the Late Jurassic (e.g. Maslanyj et al., 1992; Light et al., 1993; Clemson et al., 1997, 1999; Gallagher and Brown, 1999; Aizawa et al., 2000), and synrift sediments within the Namibian passive margin are dated to be between 130 and $150 \mathrm{Ma}$ (Clemson et al., 1997; Guillocheau et al., 2012).

There have been several suggestions for the origin of magma-rich and magma-poor margins. A suggestion for the asymmetry seen is shift of the plume centre over the mid-ocean ridge at 
93 Ma to the South American side (O'Connor and Jokat, 2015), forming the São Paulo Plateau (Fig. 2; Pérez-Díaz and Eagles, 2014). Therefore, this tectonic event could be the cause of the sharp transition from $26-28 \mathrm{~km}$ thick Walvis Ridge to the $6 \mathrm{~km}$ thin oceanic crust in Angola. Another possible explanation for the asymmetry in volcanism north and south of the Rio Grande Rise and Walvis Ridge is the role of lithosphere thickness. We have already established its importance for our numerical modelling. Taking a north-south transect of reconstructed lithosphere thickness at time of break-up (133Ma, from Moulin et al., 2013), the location of the Congo craton causes a significant increase in lithosphere thickness to the north of the approximate location of the plume axis (Fig. 15). This is coupled with slowed spreading rates in this region, ranging from $4-8 \mathrm{~mm} \mathrm{yr}^{-1}$ (Heine et al., 2013) as rifting moves northward. Sleep (1996) suggested the sublithospheric bathymetry has a profound effect on the mantle plume near a ridge axis, forming an 'upside-down drainage pattern'. Through numerical models, it was found only a relatively thin layer of plume material would spread up slope to a ridge axis, and that normal lithosphere surrounding a plume material would 'to some extent act as a levée' (e.g. Sleep, 1996; Nielsen et al., 2002). Cores in the Etendeka volcanic province, dated at magnetic isochron 15n (Dodd et al., 2015) and with an age of 135.96 Ma (Gee and Kent, 2007), confirm the presence of the plume, or at least a hot layer, before break-up of our study area. We suggest that in the southern South Atlantic, as the plume impinged the base of the lithosphere, it would have ponded towards the thinner lithosphere (Nielsen et al., 2002) and spread preferentially towards the South where extension had already commenced. As a result, it would have caused the asymmetry observed with respect to volcanism along the passive margins south and north of the Rio Grande Rise and Walvis Ridge. 


\section{Conclusions}

We identified the LaLOC location and measured initial oceanic crustal thickness for 37 seismic profiles along conjugate margins in the southern South Atlantic. We measured the along-strike distance from the commencement of the Rio Grande Rise and Walvis Ridges for all of these points and studied the spatial variability of ocean crust thickness. We found a trend of reduction in initial oceanic crustal thickness of $0.16 \mathrm{~km}$ per $100 \mathrm{~km}$ south from the Rio Grande Rise and Walvis Ridge (Fig. 8a), with thickness ranging from $11.7 \mathrm{~km}$ adjacent to the ridges, decreasing to $6.1 \mathrm{~km}$ at the most southerly point. We found no strong correlation between segment boundaries and oceanic crustal thickness (Fig. 8b and 10).

The relatively simple numerical model of continental break-up used here has previously demonstrated the importance of lithosphere thickness on break-up volcanism (Armitage et al., 2010). We used the present-day lithosphere values with the assumption of little change since break-up (McKenzie et al., 2015). By also assuming the sea floor spreading rates are indicative of the rate of extension during break-up, we then varied mantle potential and hot layer temperatures in an attempt to fit the observed age and thickness of the first oceanic crust produced.

From the long-offset ION Geophysical lines, we first determined the model asthenosphere temperature to be $1315^{\circ} \mathrm{C}$ using the observed reduction in oceanic crustal thickness with time and distance from the passive margin (Fig. 11). To match the initial oceanic crustal thicknesses from the seismic data, we found there must have been an increased temperature relative to the model asthenosphere temperature. From an initial value of $1515{ }^{\circ} \mathrm{C}$ with proximity to the Rio Grande Rise and Walvis Ridge, representing an excess temperature of $200^{\circ} \mathrm{C}$, there was a reduction of $\sim 40^{\circ} \mathrm{C}$ per $500 \mathrm{~km}$, matching the initial oceanic crustal thickness estimated from the seismic data (Fig. 14). This supports the evidence of the presence of a mantle plume or thermal anomaly as the origin for excessive melt production in our study area. In addition, our rifting duration range from $15-30 \mathrm{Myr}$, suggesting rifting had started in the Late Jurassic, in agreement with evidence from sedimentary accumulations (e.g. Clemson et al., 1997; Guillocheau et al., 2012). Therefore, while other factors, such as segmentation or sediment loading (e.g. Bialas and Buck, 2009; Koopmann et al., 2014b), can influence rift architecture, the volcanic nature of a rifted margin is fundamentally controlled by the structure of the lithosphere and asthenosphere. 
By reconstructing the lithosphere thickness at break-up, we suggest the sublithospheric topography had a strong influence on volcanism throughout the South Atlantic, including the asymmetry in volcanism along the margins. The magma-poor area north of the Rio Grande Rise and Walvis Ridge is adjacent to the Congo Craton. As previously suggested by Sleep (1996), the lateral flow of the potential mantle plume could have been hindered by this continental root. To the south of the Congo Craton, the volcanism observed due to break-up is found to be a result of a more subtle interplay between lithosphere thickness and mantle temperature.

\section{Acknowledgments}

We would like to thank Carl McDermott and Noemi G. Gyori (Imperial College London) for their contribution to the location of segments and reconstruction work respectively. We would like to thank ION Geophysical for access to their seismic lines. We would like to thank Dr. Klaus Bauer for his wide-angle datasets, Dr. Maryline Moulin for providing us with isochron locations, and Dr. Stewart Fishwick for access to his lithospheric thickness grid. The GPlates and GMT programs have also been invaluable. This work was funded by a Royal Astronomical Society fellowship and an ANR grant, InterRift, to John J. Armitage, and the John Archer Scholarship to Chandra A. Taposeea. 
Aizawa, M., Bluck, B., Cartwright, J., Milner, S., Swart, R., Ward, J., 2000. Constraints on the geomorphological evolution of Namibia from the offshore stratigraphic record. Communications of the Geological Survey of Namibia 12, 337-346.

Armante, C.; Eakins, B., 2009. ETOPO1 1 Arc-Minute Global Relief Model: Procedures, Data Sources and Analysis. Memorandum NESDIS NGDC-24, 19.

Armitage, J. J., Collier, J. S., Minshull, T. A., 2010. The importance of rift history for volcanic margin formation. Nature 465 (7300), 913-917.

Aslanian, D., Moulin, M., Olivet, J. L., Unternehr, P., Matias, L., Bache, F., Rabineau, M., Nouze, H., Klingelheofer, F., Contrucci, I., Labails, C., 2009. Brazilian and African passive margins of the Central Segment of the South Atlantic Ocean: Kinematic constraints. Tectonophysics 468 (1-4), 98-112.

Bauer, K., Neben, S., Schreckenberger, B., Emmermann, R., Hinz, K., Fechner, N., Gohl, K., Schulze, A., Trumbull, R. B., Weber, K., 2000. Deep structure of the Namibia continental margin as derived from integrated geophysical studies. Journal of Geophysical Research: Solid Earth 105 (B11), 25829-25853.

Becker, K., Franke, D., Trumbull, R., Schnabel, M., Heyde, I., Schreckenberger, B., Koopmann, H., Bauer, K., Jokat, W., Krawczyk, C., 2014. Asymmetry of high-velocity lower crust on the South Atlantic rifted margins and implications for the interplay of magmatism and tectonics in continental breakup. Solid Earth 5 (2), 1011.

Bellieni, G., Brotzu, P., Comin-Chiaramonti, P., Ernesto, M., Melfi, A., Pacca, I., Piccirilo, E., Stolfa, D., 1983. Petrological and Paleomagnetic Data on the Plateau Basalts to Rhyolite sequencies of the Southern Paraná Basin (Brazil). Anais da Academia Brasileira de Ciências $55(4), 355-383$.

Bialas, R. W., Buck, W. R., 2009. How sediment promotes narrow rifting: Application to the gulf of california. Tectonics 28 (4), TC4014.

Braun, M. G., Hirth, G., Parmentier, E., 2000. The effects of deep damp melting on mantle flow and melt generation beneath mid-ocean ridges. Earth and Planetary Science Letters 176 (3), $339-356$. 
Buiter, S. J., Torsvik, T. H., 2014. A review of wilson cycle plate margins: A role for mantle plumes in continental break-up along sutures? Gondwana Research 26 (2), 627-653.

Campbell, I. H., 2007. Testing the plume theory. Chemical Geology 241 (3-4), 153-176.

Clemson, J., Cartwright, J., Booth, J., 1997. Structural segmentation and the influence of basement structure on the Namibian passive margin. Journal of the Geological Society 154 (3), $477-482$

Clemson, J., Cartwright, J., Swart, R., 1999. The Namib Rift: a rift system of possible Karoo age, offshore Namibia. Geological Society, London, Special Publications 153 (1), 381-402.

Coffin, M. F., Eldholm, O., 1994. Large igneous provinces: crustal structure, dimensions, and external consequences. Reviews of Geophysics 32 (1), 1-36.

Collier, J. S., Minshull, T. A., Hammond, J. O. S., Whitmarsh, R. B., Kendall, J. M., Sansom, V., Lane, C. I., Rumpker, G., 2009. Factors influencing magmatism during continental breakup: New insights from a wide-angle seismic experiment across the conjugate Seychelles-Indian margins. Journal of Geophysical Research: Solid Earth 114 (B3).

Contrucci, I., Matias, L., Moulin, M., Geli, L., Klingelhofer, F., Nouze, H., Aslanian, D., Olivet, J. L., Rehault, J. P., Sibuet, J. C., 2004. Deep structure of the West African continental margin (Congo, Zaire, Angola), between 5 degrees S and 8 degrees S, from reflection/refraction seismics and gravity data. Geophysical Journal International 158 (2), 529-553.

Cordery, M. J., Morgan, J. P., 1993. Convection and melting at mid-ocean ridges. Journal of Geophysical Research: Solid Earth 98 (B11), 19477-19503.

Courtillot, V., Jaupart, C., Manighetti, I., Tapponnier, P., Besse, J., 1999. On causal links between flood basalts and continental breakup. Earth and Planetary Science Letters 166 (34), 177-195.

Dodd, S. C., Mac Niocaill, C., Muxworthy, A. R., 2015. Long duration (> 4 Ma) and steadystate volcanic activity in the early Cretaceous Paraná-Etendeka Large Igneous Province: New palaeomagnetic data from Namibia. Earth and Planetary Science Letters 414, 16-29.

Erlank, A., Marsh, J., Duncan, A., Miller, R. M., Hawkesworth, C., Betton, P., Rex, D., 1984. Geochemistry and petrogenesis of the Etendeka volcanic rocks from SWA/Namibia. Special Publication Geological Society of South Africa 13, 195-245. 
Fernandez, M., Afonso, J. C., Ranalli, G., 2010. The deep lithospheric structure of the Namibian volcanic margin. Tectonophysics 481 (1-4), 68-81.

Fishwick, S., 2010. Surface wave tomography: Imaging of the lithosphere-asthenosphere boundary beneath central and southern Africa? Lithos 120 (1), 63-73.

Fishwick, S., Bastow, I. D., 2011. Towards a better understanding of African topography: a review of passive-source seismic studies of the African crust and upper mantle. Geological Society, Special Publications 357 (1), 343-371.

Franke, D., Ladage, S., Schnabel, M., Schreckenberger, B., Reichert, C., Hinz, K., Paterlini, M., de Abelleyra, J., Siciliano, M., 2010. Birth of a volcanic margin off Argentina, South Atlantic. Geochemistry Geophysics Geosystems 11 (2).

Franke, D., Neben, S., Ladage, S., Schreckenberger, B., Hinz, K., 2007. Margin segmentation and volcano-tectonic architecture along the volcanic margin off Argentina/Uruguay, South Atlantic. Marine Geology 244 (1-4), 46-67.

Fromm, T., Planert, L., Jokat, W., Ryberg, T., Behrmann, J., Weber, M., Haberland, C., 2015. South Atlantic opening: A plume-induced breakup? Geology 43 (10), 931-934.

Gallagher, K., Brown, R., 1999. Denudation and uplift at passive margins: the record on the Atlantic Margin of southern Africa. Philosophical Transactions of the Royal Society of London A: Mathematical, Physical and Engineering Sciences 357 (1753), 835-859.

Gallagher, K., Hawkesworth, C., 1994. Mantle plumes, continental magmatism and asymmetry in the South Atlantic. Earth and Planetary Science Letters 123 (13), 105-117.

Gee, J. S., Kent, D. V., 2007. Source of oceanic magnetic anomalies and the geomagnetic polarity time scale. Treatise on Geophysics, Vol. 5: Geomagnetism, 455-507.

Gladczenko, T. P., Skogseid, J., Eldhom, O., 1998. Namibia volcanic margin. Marine Geology $20(4), 313-341$.

Griffiths, R., Campbell, I., 1991. Interaction of mantle plume heads with the Earth's surface and onset of small-scale convection. Journal of Geophysical Research: Solid Earth 96 (B11), $18295-18310$. 
Griffiths, R. W., Campbell, I. H., 1990. Stirring and structure in mantle starting plumes. Earth and Planetary Science Letters 99 (1), 66-78.

Gubanov, A., Mooney, W., 2009. New global geological maps of crustal basement age. In: AGU Fall Meeting Abstracts. Vol. 1. p. 1583.

Guillocheau, F., Rouby, D., Robin, C., Helm, C., Rolland, N., Le Carlier de Veslud, C., Braun, J., 2012. Quantification and causes of the terrigeneous sediment budget at the scale of a continental margin: a new method applied to the Namibia-South Africa margin. Basin Research $24(1), 3-30$.

Hawkesworth, C., Gallagher, K., Kelley, S., Mantovani, M., Peate, D., Regelous, M., Rogers, N., 1992. Paraná magmatism and the opening of the South Atlantic. Geological Society, Special Publications 68 (1), 221-240.

Heine, C., Zoethout, J., Müller, R. D., 2013. Kinematics of the South Atlantic rift. Solid Earth $4(2), 215-253$.

Herzberg, C., Asimow, P. D., Arndt, N., Niu, Y., Lesher, C. M., Fitton, J. G., Cheadle, M. J., Saunders, A. D., 2007. Temperatures in ambient mantle and plumes: Constraints from basalts, picrites, and komatiites. Geochemistry, Geophysics, Geosystems 8 (2), Q02006.

Hinz, K., 1981. A hypothesis on terrestrial catastrophes: wedges of very thick oceanward dipping layers beneath passive continental margins; their origin and paleoenvironmental significance. Geologisches Jahrbuch, Reihe E: Geophysics, 3-28.

Hinz, K., Neben, S., Schreckenberger, B., Roeser, H., Block, M., Souza, K., Meyer, H., 1999. The Argentine continental margin north of 48 S: sedimentary successions, volcanic activity during breakup. Marine and Petroleum Geology 16 (1), 1-25.

Hinz, K., Popovici, A., Ronda, C., Beisner, H., 1988. On a multichannel seismic reconnaissance survey of the Argentine eastern continental margin by RV Explora. Tech. rep., Internal Report 102.371, Bundesantalt fur Geowissenschaften und Rohsthoffe, Hannover.

Hirsch, K. K., Bauer, K., Scheck-Wenderoth, M., 2009. Deep structure of the western South African passive margin - Results of a combined approach of seismic, gravity and isostatic investigations. Tectonophysics 470 (1-2), 57-70. 
Holbrook, W. S., Larsen, H., Korenaga, J., Dahl-Jensen, T., Reid, I. D., Kelemen, P., Hopper, J., Kent, G., Lizarralde, D., Bernstein, S., et al., 2001. Mantle thermal structure and active upwelling during continental breakup in the North Atlantic. Earth and Planetary Science Letters 190 (3), 251-266.

Hopper, J. R., Mutter, J. C., Larson, R. L., Mutter, C. Z., 1992. Magmatism and rift margin evolution: Evidence from northwest Australia. Geology 20 (9), 853-857.

Houseman, G., 1990. The thermal structure of mantle plumes: axisymmetric or triple-junction? Geophysical Journal International 102 (1), 15-24.

Ito, G., Lin, J., Gable, C. W., 1996. Dynamics of mantle flow and melting at a ridge-centered hotspot: Iceland and the Mid-Atlantic Ridge. Earth and Planetary Science Letters 144 (12), $53-74$.

Jungslager, E. H., 1999. Petroleum habitats of the Atlantic margin of South Africa. Geological Society, London, Special Publications 153 (1), 153-168.

Koopmann, H., Brune, S., Franke, D., Breuer, S., 2014a. Linking rift propagation barriers to excess magmatism at volcanic rifted margins. Geology 42 (12), 1071-1074.

Koopmann, H., Franke, D., Schreckenberger, B., Schulz, H., Hartwig, A., Stollhofen, H., di Primio, R., 2014b. Segmentation and volcano-tectonic characteristics along the SW African continental margin, South Atlantic, as derived from multichannel seismic and potential field data. Marine and Petroleum Geology 50, 22-39.

Light, M., Maslanyj, M., Greenwood, R., Banks, N., 1993. Seismic sequence stratigraphy and tectonics offshore namibia. Geological Society, London, Special Publications 71 (1), 163-191.

Lizarralde, D., Axen, G. J., Brown, H. E., Fletcher, J. M., González-Fernández, A., Harding, A. J., Holbrook, W. S., Kent, G. M., Paramo, P., Sutherland, F., et al., 2007. Variation in styles of rifting in the Gulf of California. Nature 448 (7152), 466-469.

Maslanyj, M. P., Light, M. P. R., Greenwood, R. J., Banks, N. L., 1992. Extension tectonics offshore Namibia and evidence for passive rifting in the South-Atlantic. Marine and Petroleum Geology 9 (6), 590-601. 
Maus, S., Barckhausen, U., Berkenbosch, H., Bournas, N., Brozena, J., Childers, V., Dostaler, F., Fairhead, J., Finn, C., Von Frese, R., et al., 2009. EMAG2: A 2-arc min resolution Earth Magnetic Anomaly Grid compiled from satellite, airborne, and marine magnetic measurements. Geochemistry, Geophysics, Geosystems 10 (8), Q08005.

Maus, S., Sazonova, T., Hemant, K., Fairhead, J., Ravat, D., 2007. National geophysical data center candidate for the world digital magnetic anomaly map. Geochemistry, Geophysics, Geosystems 8 (6), Q06017.

McKenzie, D., Bickle, M., 1988. The volume and composition of melt generated by extension of the lithosphere. Journal of Petrology 29 (3), 625-679.

McKenzie, D., Daly, M. C., Priestley, K., 2015. The lithospheric structure of pangea. Geology $43(9), 783-786$.

McKenzie, D., Jackson, J., Priestley, K., 2005. Thermal structure of oceanic and continental lithosphere. Earth and Planetary Science Letters 233 (3), 337-349.

Minshull, T. A., Lane, C. I., Collier, J. S., Whitmarsh, R. B., 2008. The relationship between rifting and magmatism in the northeastern Arabian Sea. Nature Geoscience 1 (7), 463-467.

Moresi, L., Zhong, S., Gurnis, M., 1996. The accuracy of finite element solutions of Stokes's flow with strongly varying viscosity. Physics of the Earth and Planetary Interiors 97 (1), 83-94.

Moulin, M., Aslanian, D., Rabineau, M., Patriat, M., Matias, L., 2013. Kinematic keys of the Santos-Namibe basins. Geological Society, Special Publications 369 (1), 91-107.

Moulin, M., Aslanian, D., Unternehr, P., 2010. A new starting point for the South and Equatorial Atlantic Ocean. Earth-Science Reviews 98 (1), 1-37.

Nielsen, T. K., Hopper, J. R., 2004. From rift to drift: Mantle melting during continental breakup. Geochemistry, Geophysics, Geosystems 5 (7), Q07003.

Nielsen, T. K., Larsen, H. C., Hopper, J. R., 2002. Contrasting rifted margin styles south of Greenland: implications for mantle plume dynamics. Earth and Planetary Science Letters $200(3), 271-286$. 
O'Connor, J. M., Duncan, R. A., 1990. Evolution of the Walvis Ridge-Rio Grande Rise Hot Spot System: Implications for African and South American Plate motions over plumes. Journal of Geophysical Research: Solid Earth 95 (B11), 17475-17502.

O'Connor, J. M., Jokat, W., 2015. Tracking the Tristan-Gough mantle plume using discrete chains of intraplate volcanic centers buried in the Walvis Ridge. Geology 43 (8), 715-718.

O'Connor, J. M., Jokat, W., Le Roex, A. P., Class, C., Wijbrans, J. R., Keßling, S., Kuiper, K. F., Nebel, O., 2012. Hotspot trails in the South Atlantic controlled by plume and plate tectonic processes. Nature Geoscience 5 (10), 735-738.

Peate, D. W., 1997. The paraná-etendeka province. Large igneous provinces: Continental, oceanic, and planetary flood volcanism, 217-245.

Peate, D. W., Hawkesworth, C. J., Mantovani, M. S., 1992. Chemical stratigraphy of the Paraná lavas (South America): classification of magma types and their spatial distribution. Bulletin of Volcanology 55 (1-2), 119-139.

Pérez-Díaz, L., Eagles, G., 2014. Constraining South Atlantic growth with seafloor spreading data. Tectonics 33 (9), 1848-1873.

Phipps Morgan, J., 2001. Thermodynamics of pressure release melting of a veined plum pudding mantle. Geochemistry, Geophysics, Geosystems 2 (4).

Priestley, K., McKenzie, D., 2006. The thermal structure of the lithosphere from shear wave velocities. Earth and Planetary Science Letters 244 (1), 285-301.

Putirka, K. D., 2005. Mantle potential temperatures at Hawaii, Iceland, and the mid-ocean ridge system, as inferred from olivine phenocrysts: Evidence for thermally driven mantle plumes. Geochemistry Geophysics Geosystems 6 (5), Q05L08.

Renne, P. R., Ernesto, M., Pacca, I. G., Coe, R. S., Glen, J., Prévot, M., Perrin, M., et al., 1992. The age of Paraná flood volcanism, rifting of Gondwanaland, and the Jurassic-Cretaceous boundary. Science 258 (5084), 975-979.

Reston, T. J., 2010. The opening of the central segment of the South Atlantic: symmetry and the extension discrepancy 16 (3), 199-206. 
Rosendahl, B. R., 1987. Architecture of continental rifts with special reference to East Africa. Annual Review of Earth and Planetary Sciences 15, 445.

Sandwell, D., Garcia, E., Soofi, K., Wessel, P., Chandler, M., Smith, W. H., 2013. Toward 1mGal accuracy in global marine gravity from CryoSat-2, Envisat, and Jason-1. The Leading Edge 32 (8), 892-899.

Schinkel, J., 2006. Tiefenstruktur der Kontinent-Ozean-Grenze vor dem Orange Fluss, Namibia.

Schnabel, M., Franke, D., Engels, M., Hinz, K., Neben, S., Damm, V., Grassmann, S., Pelliza, H., Dos Santos, P. R., 2008. The structure of the lower crust at the Argentine continental margin, South Atlantic at 44 degrees S. Tectonophysics 454 (1-4), 14-22.

Scott, D. R., 1992. Small-scale convection and mantle melting beneath mid-ocean ridges. Geophysical Monograph - American Geophysical Union 71, 327-352.

Seton, M., Müller, R., Zahirovic, S., Gaina, C., Torsvik, T., Shephard, G., Talsma, A., Gurnis, M., Turner, M., Maus, S., et al., 2012. Global continental and ocean basin reconstructions since 200Ma. Earth-Science Reviews 113 (3), 212-270.

Sleep, N. H., 1996. Lateral flow of hot plume material ponded at sublithospheric depths. Journal of Geophysical Research 101 (B12), 28065-28083.

Sleep, N. H., 2006. Mantle plumes from top to bottom. Earth-Science Reviews 77 (4), 231-271.

Stewart, K., Turner, S., Kelley, S., Hawkesworth, C., Kirstein, L., Mantovani, M., 1996. 3-D ${ }^{40} \mathrm{Ar}-{ }^{39} \mathrm{Ar}$ geochronology in the Paraná continental flood basalt province. Earth and Planetary Science Letters 143 (1), 95-109.

Storey, B. C., 1995. The role of mantle plumes in continental breakup: case histories from Gondwanaland. Nature 377 (6547), 301-308.

Torsvik, T. H., Rousse, S., Labails, C., Smethurst, M. A., 2009. A new scheme for the opening of the South Atlantic Ocean and the dissection of an Aptian salt basin. Geophysical Journal International 177 (3), 1315-1333.

Trumbull, R. B., 2014. Causes and consequences of continental breakup in the South Atlantic: lessons learned from the SAMPLE program. In: EGU General Assembly Conference Abstracts. Vol. 16. p. 1430. 
Trumbull, R. B., Franke, D., Bauer, K., Sobolev, S. V., 2015. Petrophysical models of high velocity lower crust on the South Atlantic rifted margins: whence the asymmetry? In: EGU General Assembly Conference Abstracts. Vol. 17. p. 10976.

Turner, S., Regelous, M., Kelley, S., Hawkesworth, C., Mantovani, M., 1994. Magmatism and continental break-up in the South Atlantic: high precision ${ }^{40} \mathrm{Ar}-{ }^{39} \mathrm{Ar}$ geochronology. Earth and Planetary Science Letters 121 (3), 333-348.

White, R., McKenzie, D., 1989. Magmatism at Rift Zones - the Generation of Volcanic Continental Margins and Flood Basalts. Journal of Geophysical Research: Solid Earth 94 (B6), $7685-7729$.

White, R., McKenzie, D., 1995. Mantle plumes and flood basalts. Journal of Geophysical Research 100 (B9), 17543-17585.

White, R. S., McKenzie, D., O’Nions, R. K., 1992. Oceanic crustal thickness from seismic measurements and rare earth element inversions. Journal of Geophysical Research: Solid Earth 97 (B13), 19683-19715.

Winterbourne, J., White, N., Crosby, A., 2014. Accurate measurements of residual topography from the oceanic realm. Tectonics 33 (6), 982-1015. 


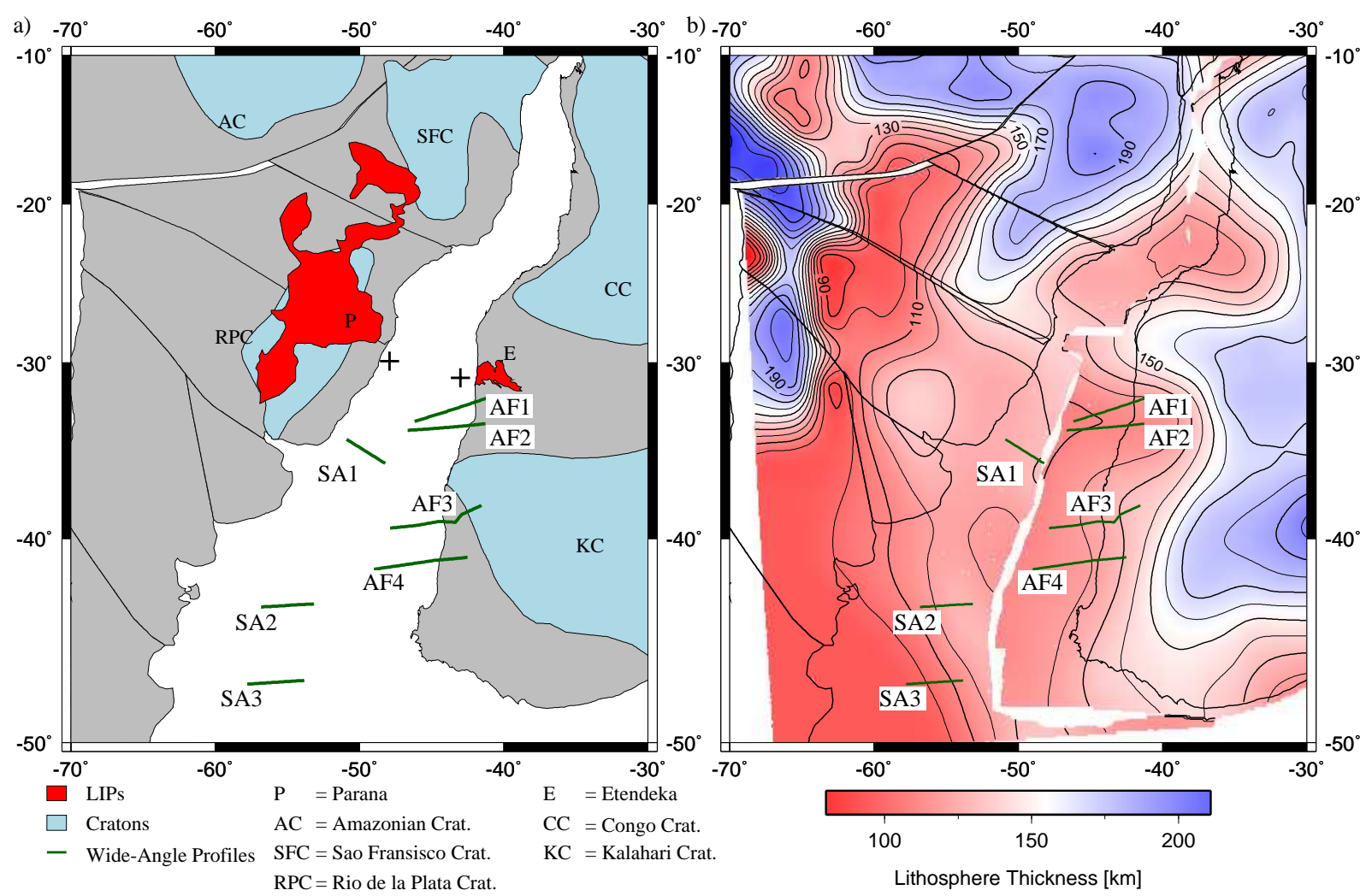

Figure 1: Reconstructions using GPlates shown at $121 \mathrm{Ma}$ using rotation poles of Moulin et al. (2010) with the sub-plates of South America (thin black lines). (a) Reconstruction showing the major geological features. The positions of cratons are from Gubanov and Mooney (2009), the location of the Etendeka-Paraná flood basalts is Coffin and Eldholm (1994). The seven wide angle seismic profiles used in this study are labelled AF1 to AF4 and SA1 to SA3. The ' + ' marks the reconstructed landfall of the Rio Grande Rise and Walvis Ridge. (b) Reconstruction of lithosphere thickness using the data set of Priestley and McKenzie (2006), the latter covering the whole area. 


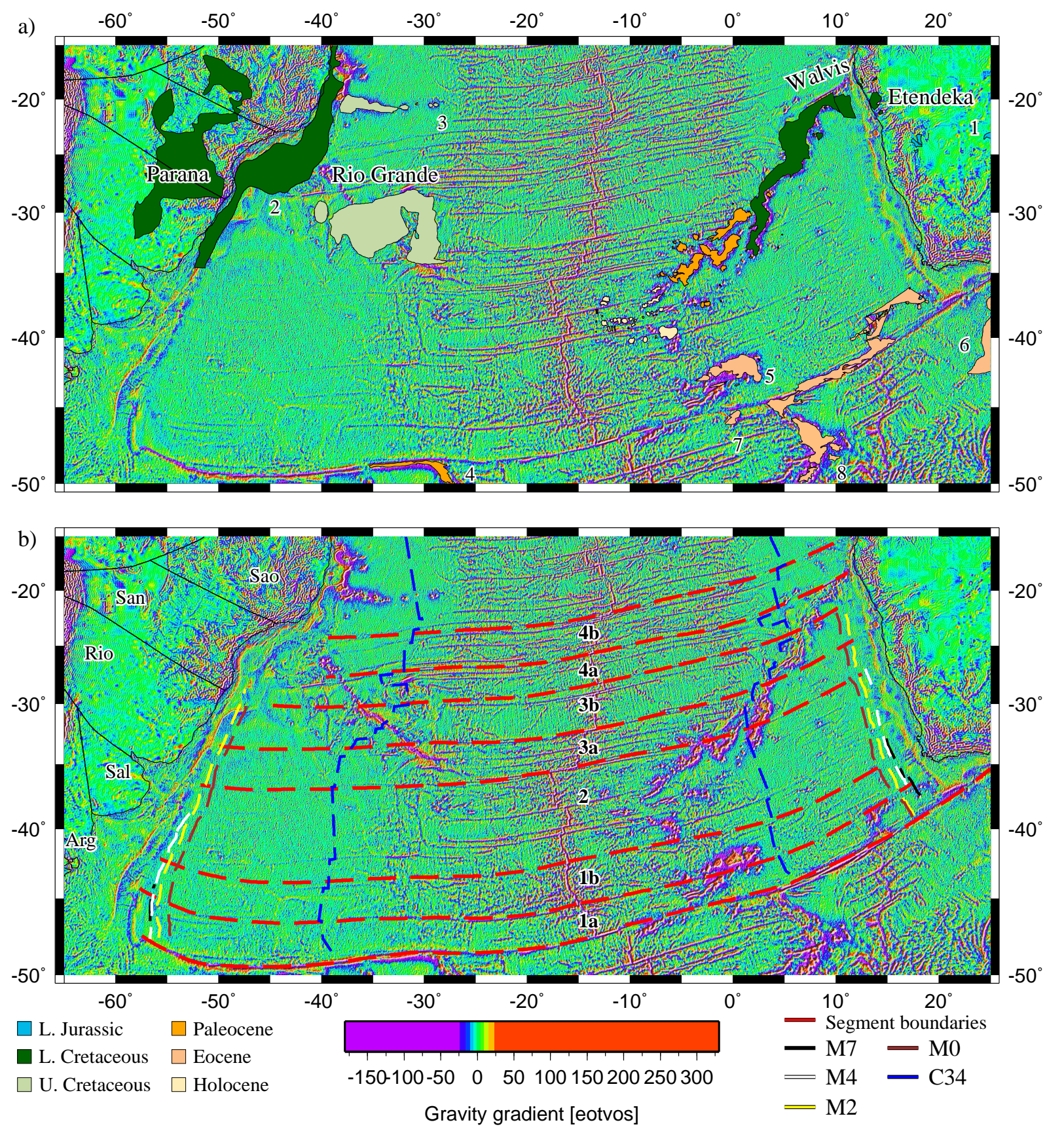

Figure 2: Map of the gravity gradient from Sandwell et al. (2013) for our study area. (a) Main tectonic features with age progressive LIPs (Coffin and Eldholm, 1994): 1=Karoo, 2= Sao Paolo, 3=Vitoria-Trinidade, $4=$ Falkland $5=$ Discovery, $6=$ Agulhas Plateau, $7=$ Hardman volcano, and $8=$ Meteor Ridge. Also shown are the sub-plate boundaries (thin black lines) from Moulin et al. (2010). (b) Interpreted location of the major segment boundaries. We identify 4 major segments (numbered 1-4) consistent with the sub-plate boundaries of South America from Moulin et al. (2010). Also shown are sea floor spreading magnetic anomalies M7, M4, M2 \& M0 from Moulin et al. (2010), C34 from Seton et al. (2012). Sub-plates: Arg = Argentina, Sal = Salado, Rio $=$ Rio de la Plata, San $=$ Santos, Sao $=$ São Francisco. 


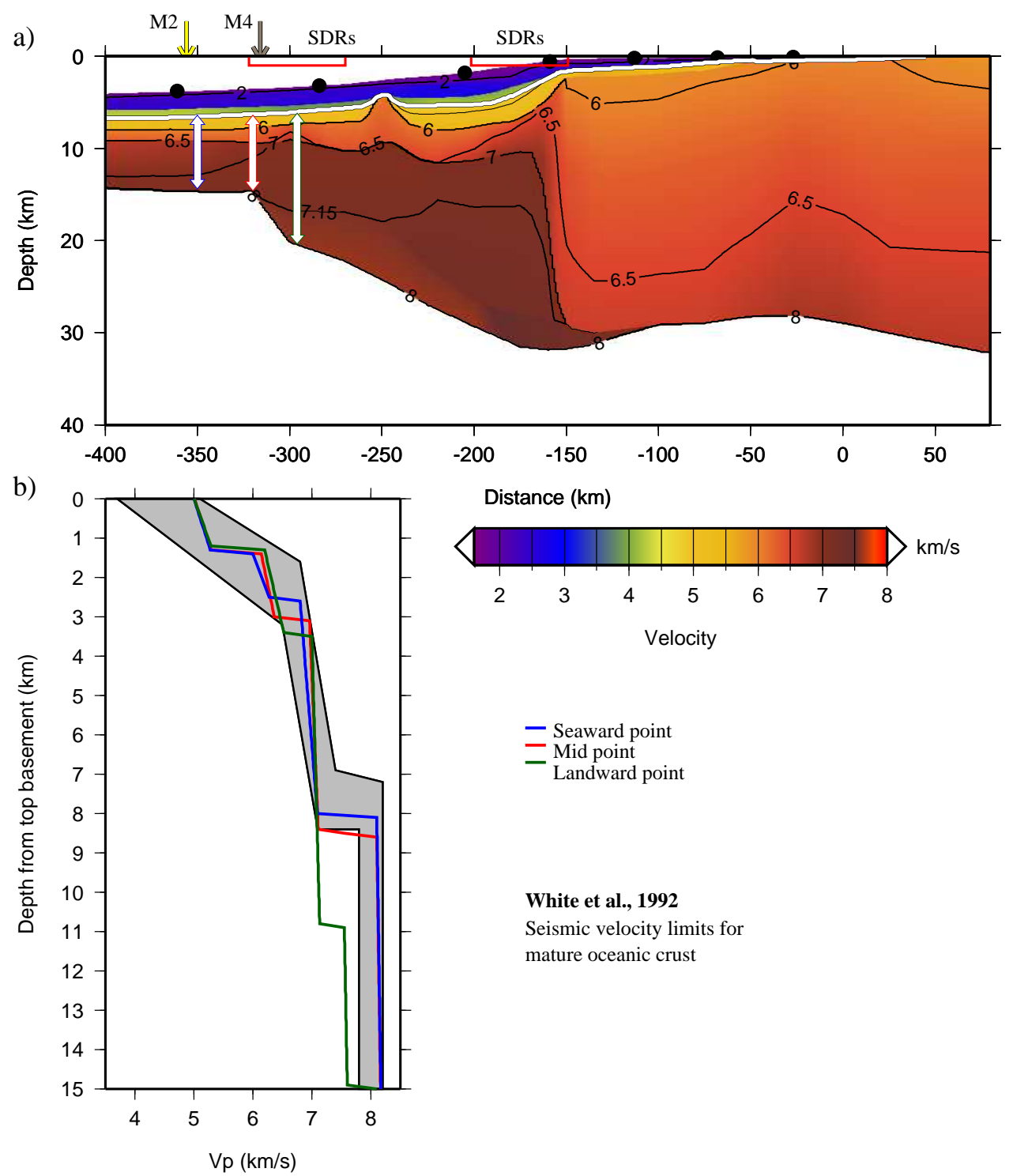

Figure 3: Example of oceanic crustal thickness measurement at the Landward Limit of Oceanic Crust (LaLOC), using the AF2 seismic velocity profile (Bauer et al., 2000). (a) Depth- $\mathrm{V}_{p}$ profile showing positions of SDRs (red boxes) and OBS locations (black circles) from Bauer et al. (2000), and magnetic anomaly M4 (grey arrow) from Moulin et al. (2010). White arrows are potential locations for LaLOC that are compared to the White et al. (1992) seismic velocity boundaries for mature oceanic crust in part b. (b) Depth- $\mathrm{V}_{p}$ plot for the three test locations for the LaLOC (white arrows) and the seismic velocity limits for mature oceanic crust (grey shading) from White et al. (1992). The mid and seaward points are within the seismic velocity boundaries and can be considered as oceanic. As the LaLOC location is the first instance of ocean crust, the mid point is therefore the LaLOC for AF2. 


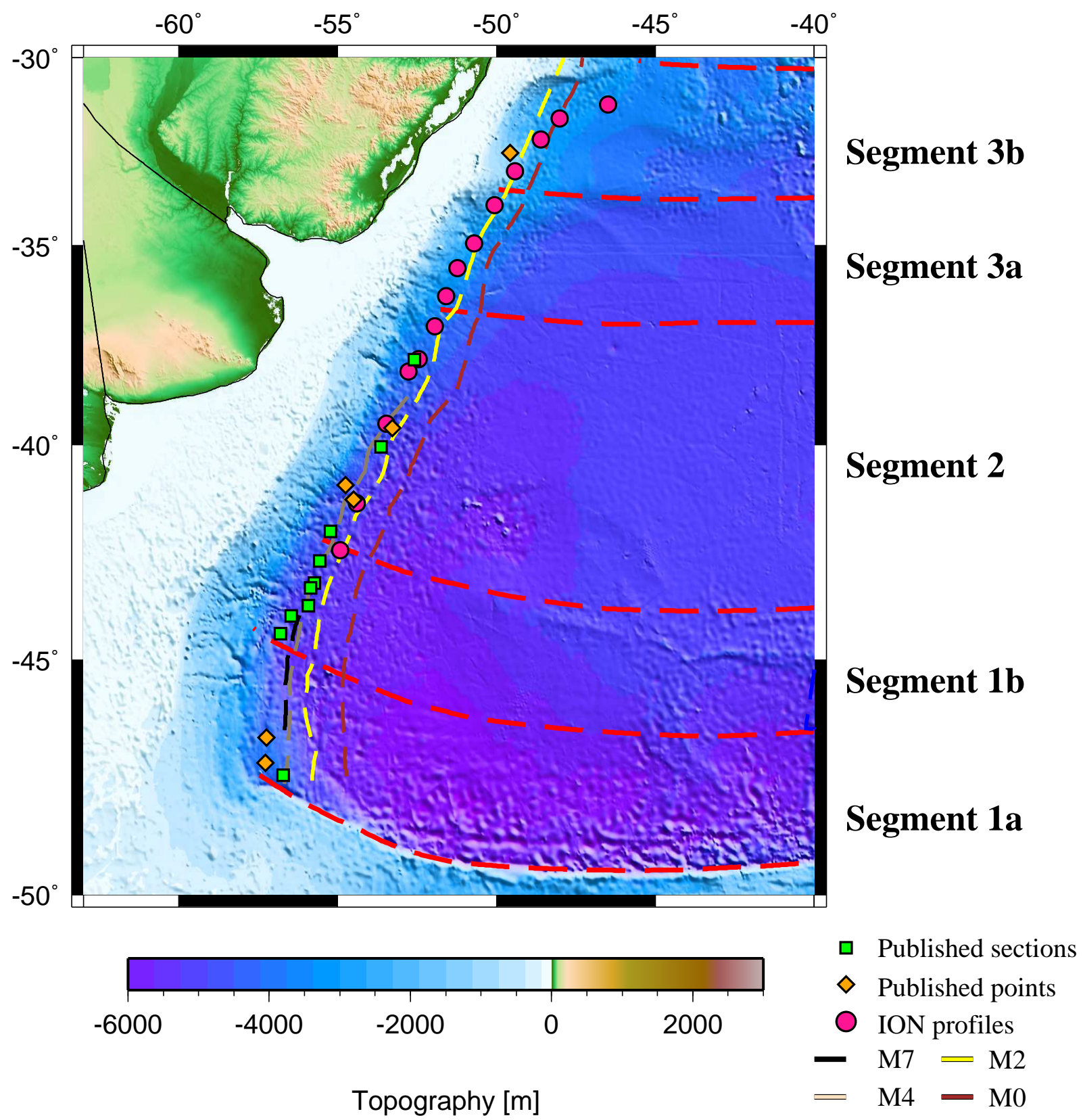

Figure 4: Map of the Landward Limit of Oceanic Crust (LaLOC) locations for all MCS profiles used in this study (Table 1). Topography and bathymetry is from ETOP01 Armante (2009). The sea floor spreading magnetic anomalies (M0, M2, M4 and M7) and plate boundaries (thin black lines) are from Moulin et al. (2010). The data is divided into three types: (1) published sections from Franke et al. (2007), Franke et al. (2010) and Hinz et al. (1999) (Fig. S3-S6), (2) published points from Winterbourne et al. (2014) (Fig. S7), and (3) ION Geophysical MCS data. 

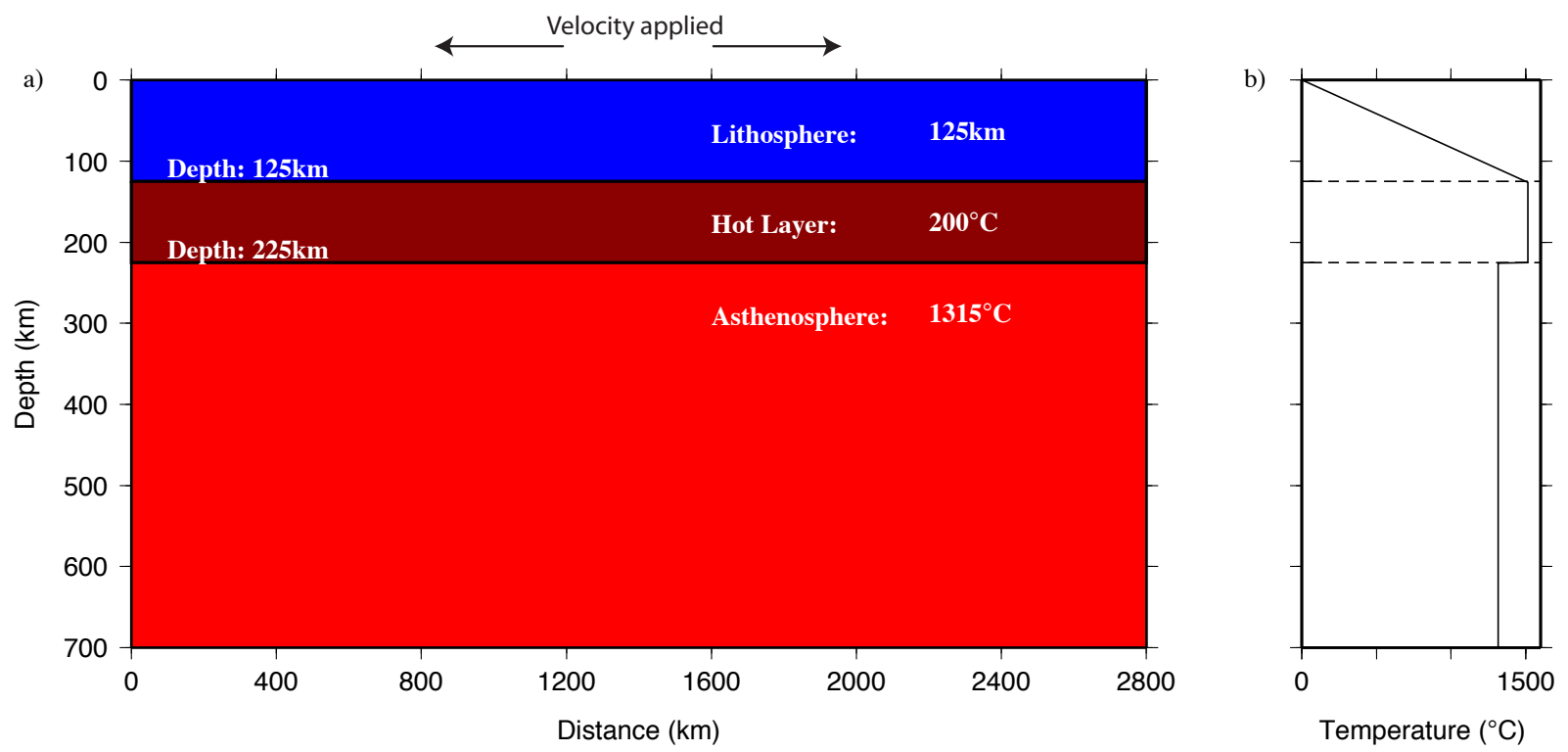

Figure 5: Example of the initial conditions for the numerical model. (a) Model domain for the 2D simulation. Extension is driven by a divergent velocity boundary condition on the upper surface. The initial lithosphere thickness is within the range of 95 and $140 \mathrm{~km}$, and the hot layer is assumed to have a thickness of $100 \mathrm{~km}$ and a temperature of 50 to $200^{\circ} \mathrm{C}$ in excess of the model asthenosphere temperature. (b) An example of an initial temperature profile with depth, where in this case the model asthenosphere temperature is $1315^{\circ} \mathrm{C}$ and the hot layer has an excess temperature of $200^{\circ} \mathrm{C}$. 

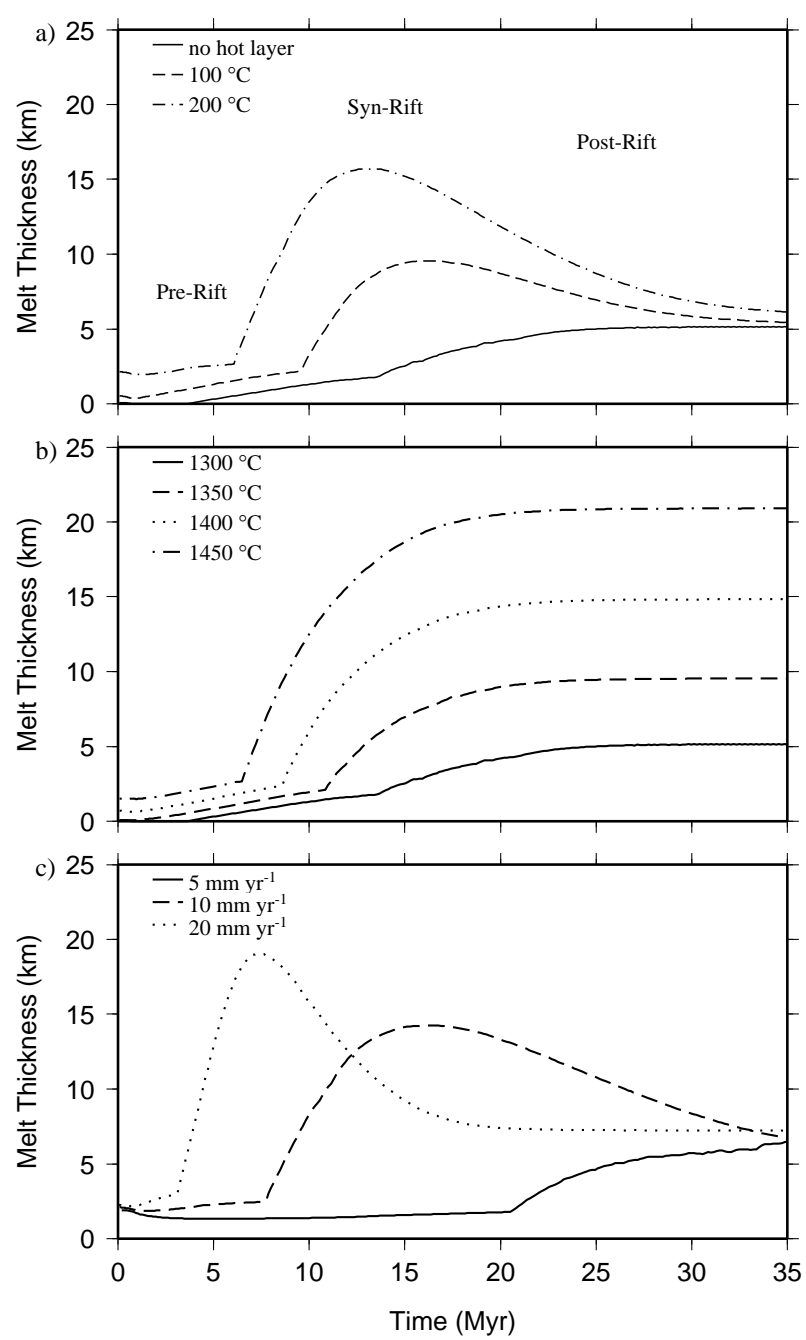

Figure 6: Base model runs to demonstrate dependence of melt production on initial model parameters. All models have an initial lithosphere thickness of $125 \mathrm{~km}$ and spreading rate of $12 \mathrm{~mm} \mathrm{yr}^{-1}$ unless otherwise specified. (a) Varying hot layer temperatures, with a $1300^{\circ} \mathrm{C}$ model asthenosphere temperature. The interpreted location of the pre, syn and post-rift phases are shown. (b) Varying model asthenosphere temperatures. (c) Differing spreading rates with a $1300^{\circ} \mathrm{C}$ model asthenosphere temperature and a $200{ }^{\circ} \mathrm{C}$ hot layer. 
10 Million Years
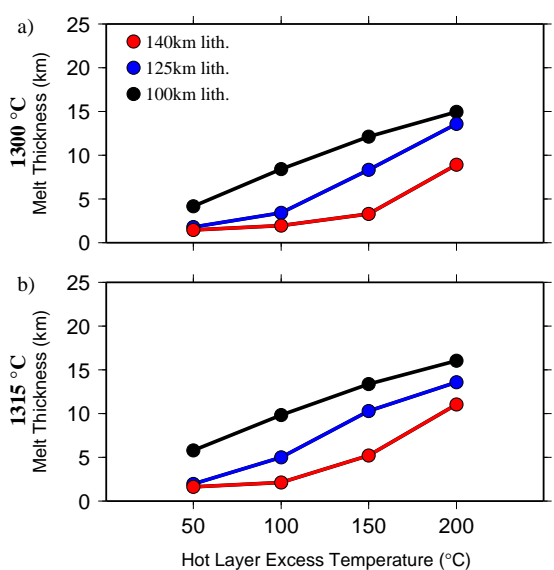

15 Million Years
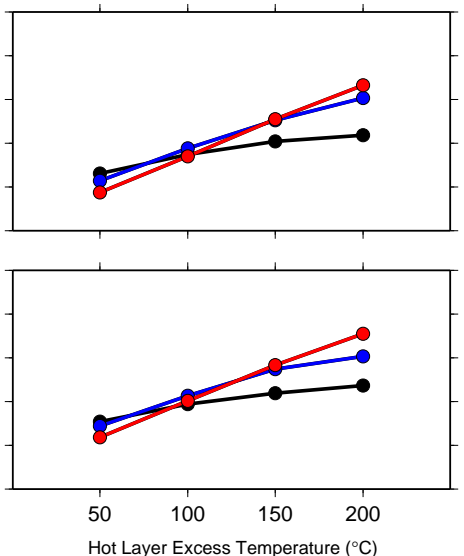

20 Million Years
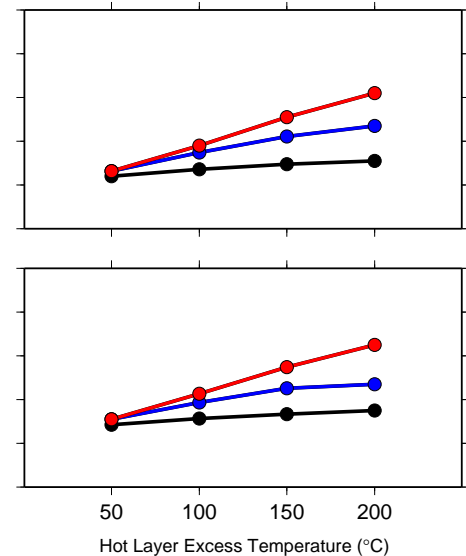

Figure 7: Evolution plots for differing initial lithosphere thickness and excess hot layer temperature. Melt thickness at 10,15 and $20 \mathrm{Myr}$ after the initiation of extension for an asthenosphere temperature of $1300{ }^{\circ} \mathrm{C}$ (a) and $1315^{\circ} \mathrm{C}$ (b). In all cases, there is a spreading rate of $12 \mathrm{~mm} \mathrm{yr}^{-1}$. Note how varying initial lithosphere thickness results in the peak magmatism occurring at different times.
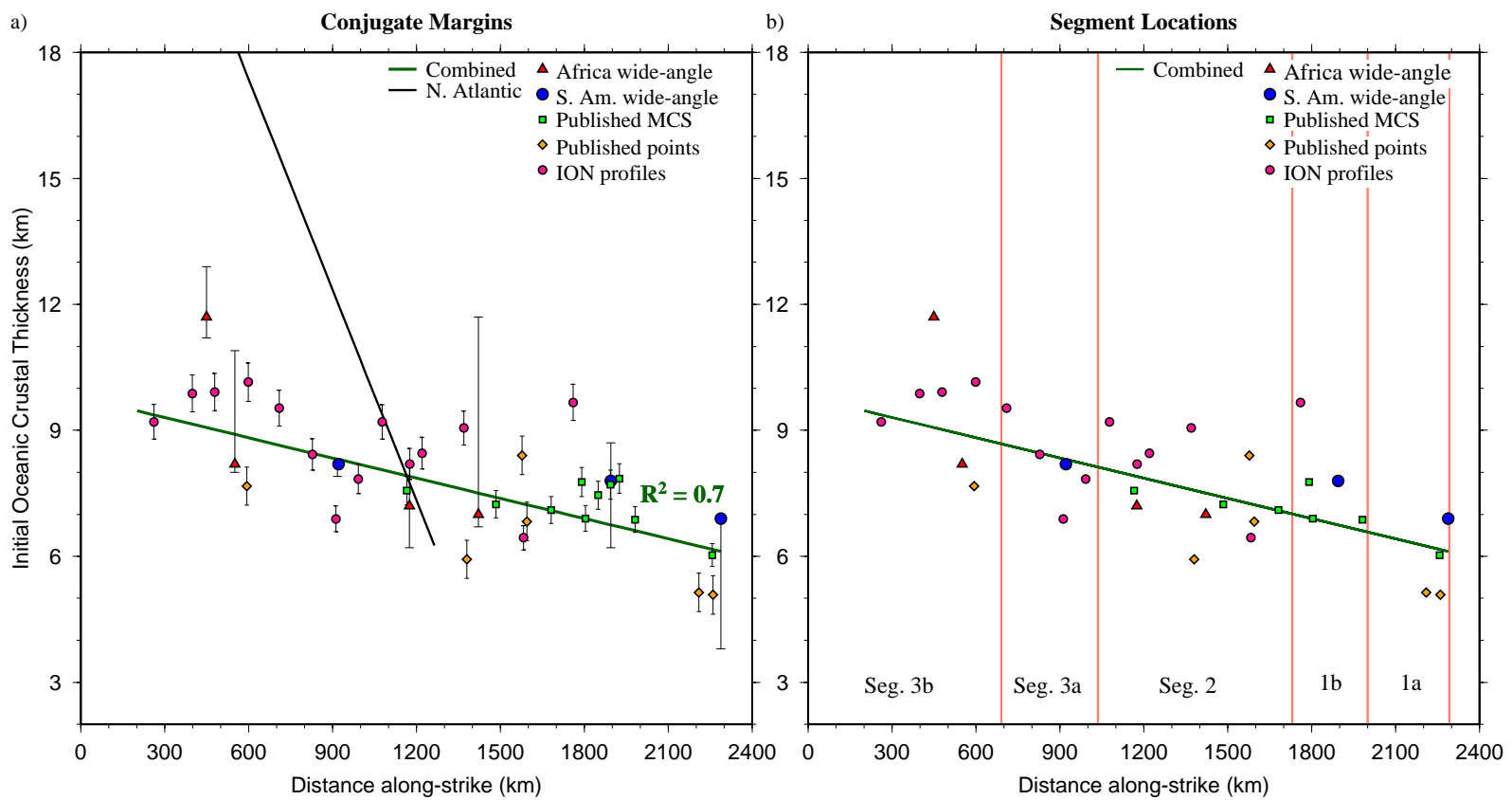

Figure 8: Initial oceanic crustal thickness plotted against distance along-strike. Data sources are given in Table 1. (a) Initial oceanic crustal thickness versus distance along-strike for all measured locations. The error bars on individual measurement points come from the uncertainty in locating LaLOC on individual profiles (Table S1). Regression analysis shows a reasonable linear relationship (green line with a regression coefficient, $\mathrm{R}^{2}=0.7$ ). For comparison, the trend found for the initial oceanic crustal thickness in the North Atlantic is shown by the black line (from Collier et al., 2009). (b) Initial oceanic crustal thickness shown relative to segment boundaries (red lines). 


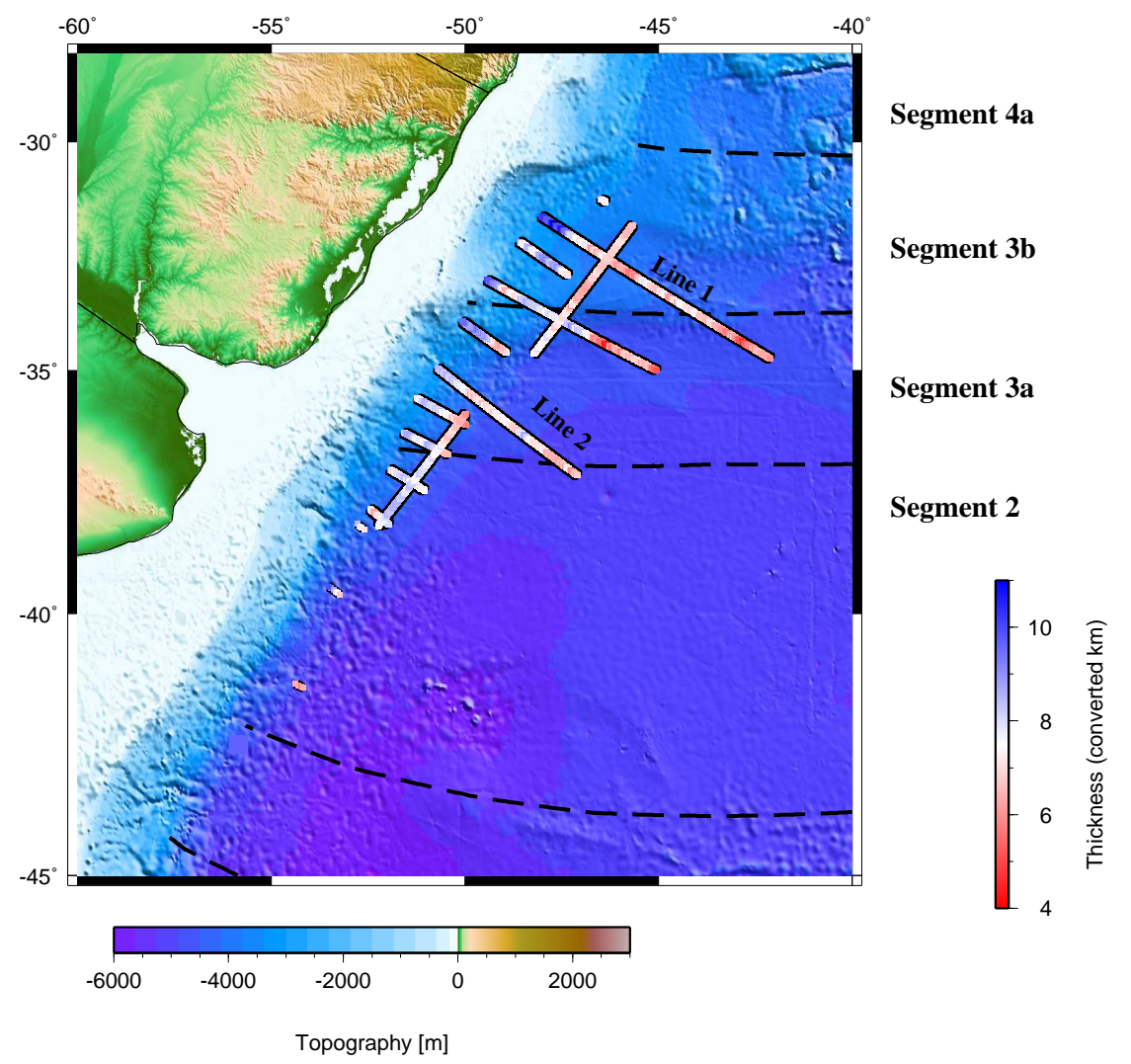

Figure 9: Ocean Crustal Thickness from the ION Geophysical long-offset data, which was measured in TWTT and converted to kilometres assuming a mean $\mathrm{V}_{p}$ value for oceanic crust of $6.7 \mathrm{~km} \mathrm{~s}^{-1}$ (White et al., 1992). Line 1 and 2 are show in detail in Fig. 10. 
Age (Ma)
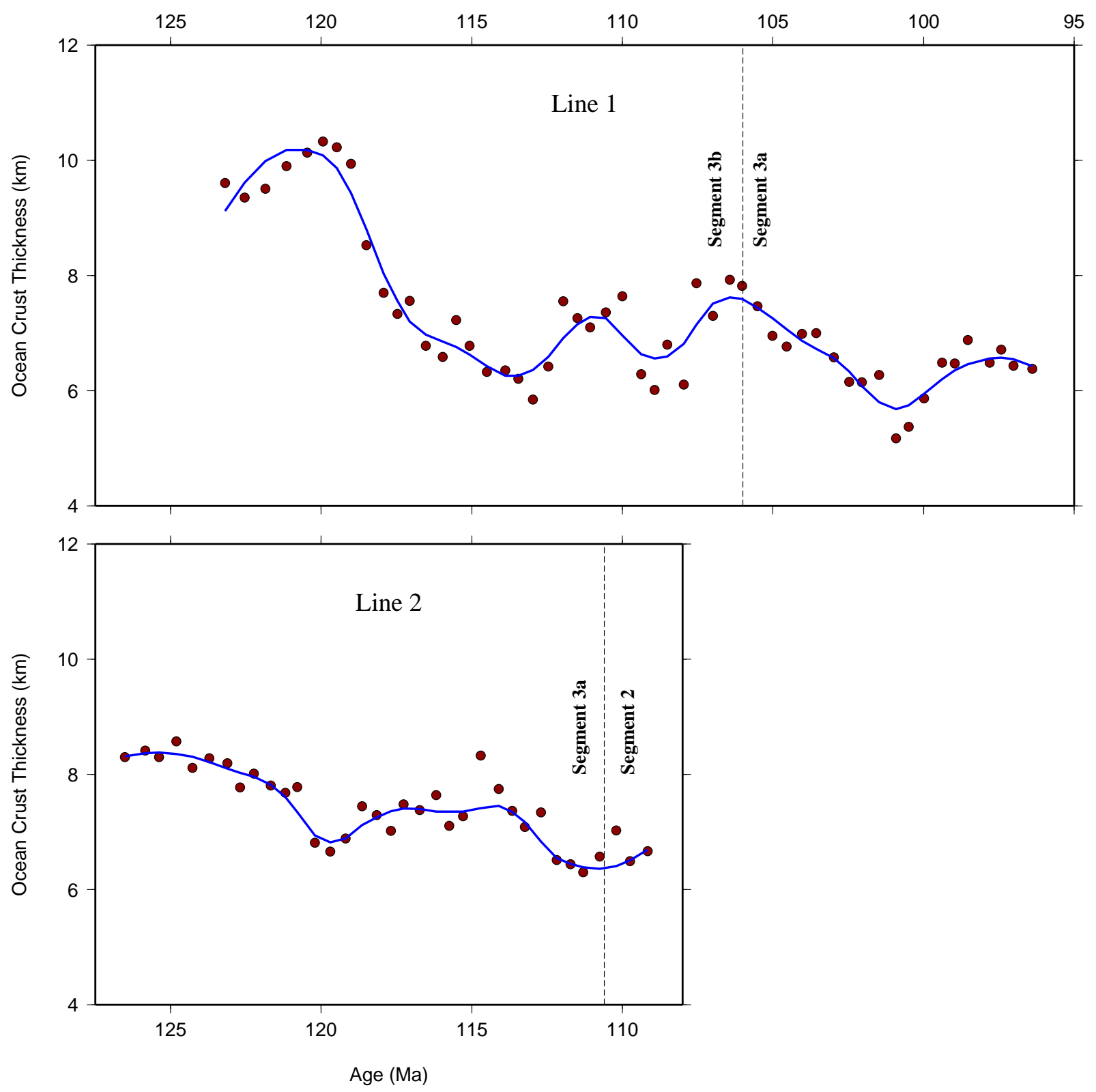

Figure 10: Ocean crustal thickness from two of the ION Geophysical long-offset data plotted against age. Locations of Lines 1 and 2 are found in Fig. 9. Ages assigned in accordance to the Gee and Kent (2007) time scale and Moulin et al. (2010) magnetic isochrons. Thickness averaged over 1.5 Myr bins (maroon dots), and smoothed with a Gaussian filer (blue lines). 


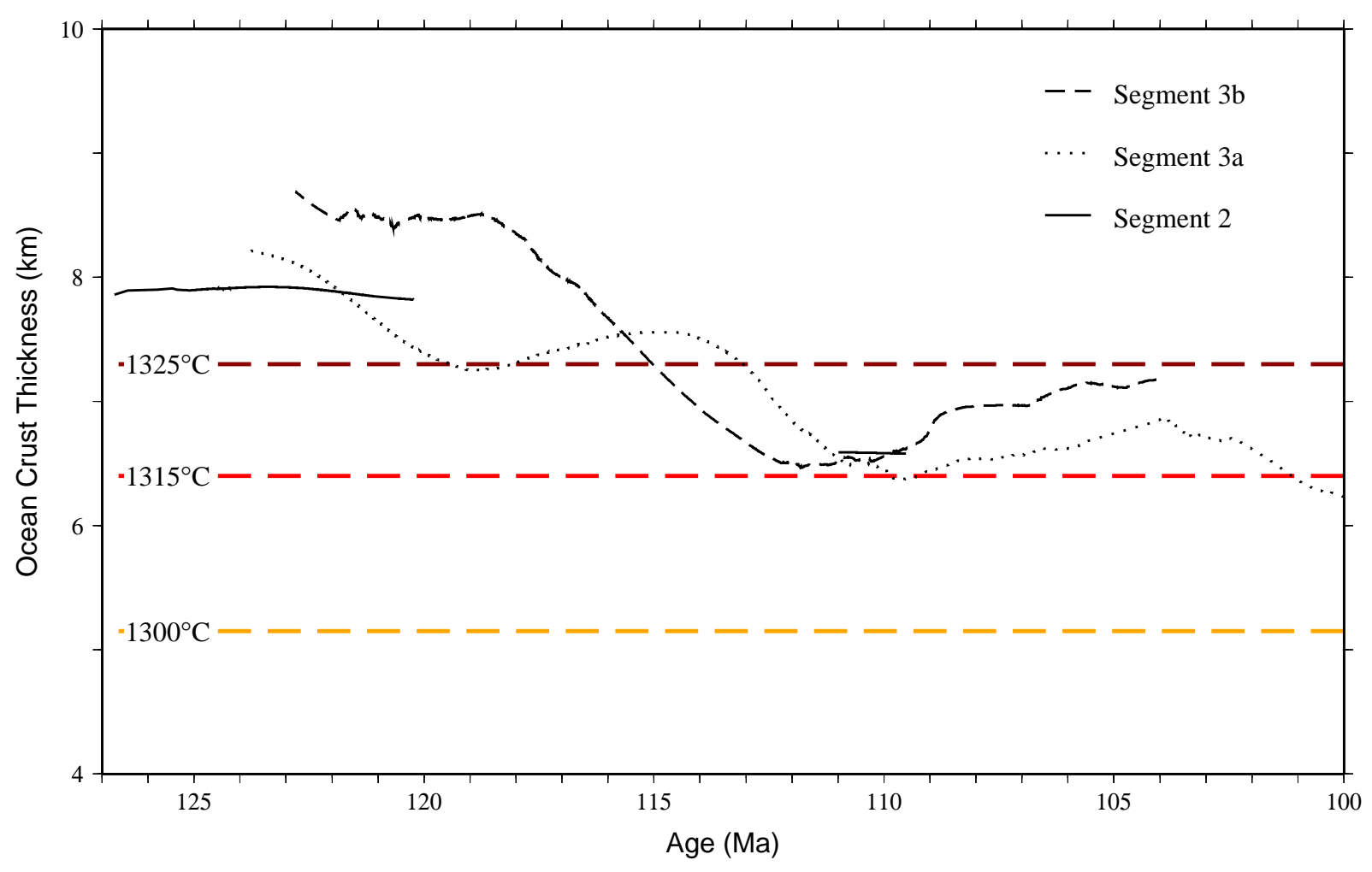

Figure 11: Determining the model asthenosphere temperature using ocean crust thicknesses from the long-offset ION Geophysical lines. All oceanic crustal thickness measurements within a given segment were averaged into 1.5 Myr bins. We test for several model asthenosphere temperatures, in this case 1300,1315 and $1325^{\circ} \mathrm{C}$, electing to use $1315^{\circ} \mathrm{C}$ as our model asthenosphere temperature in all of our subsequent models. 

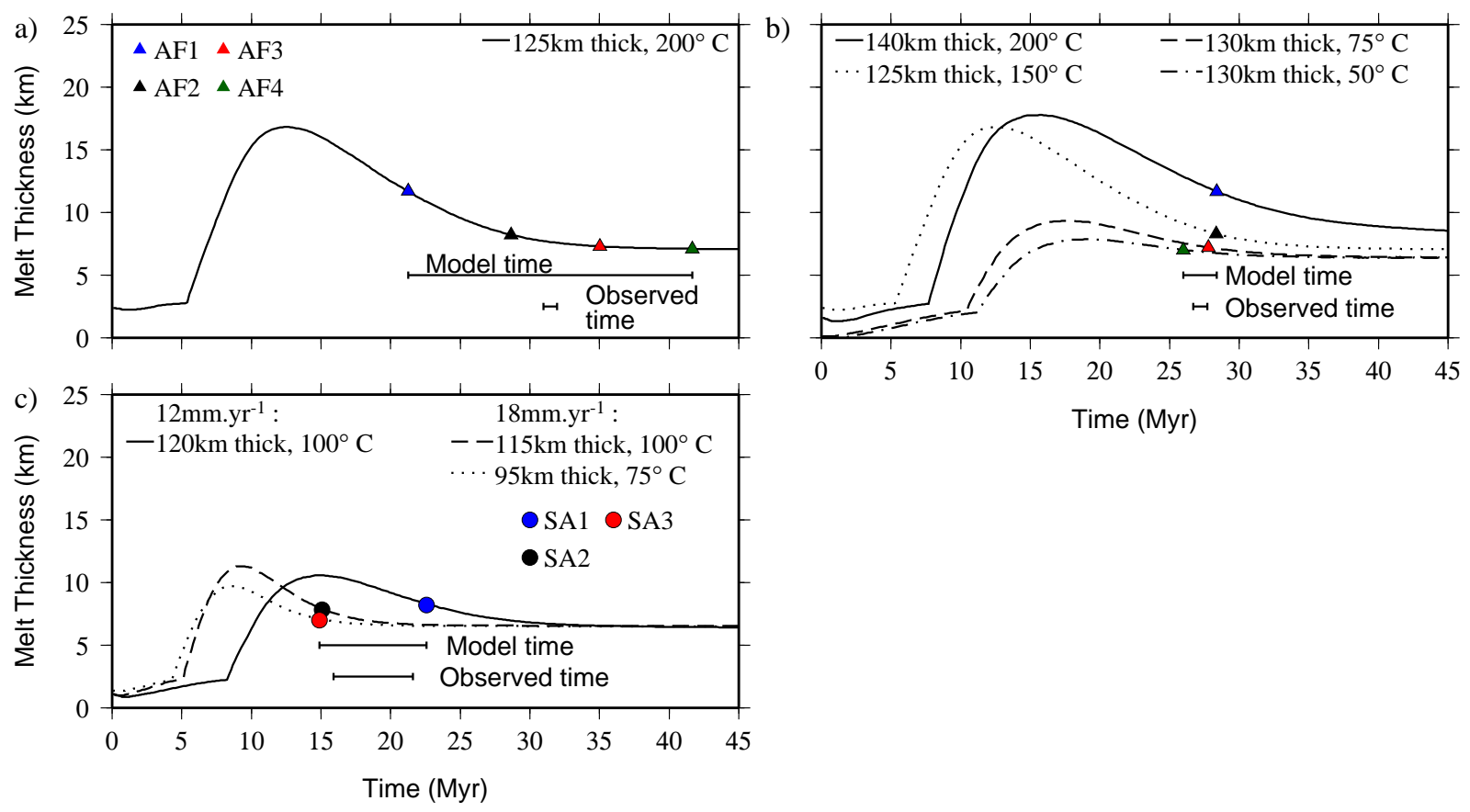

Figure 12: Models results for wide-angle profiles. Model asthenosphere temperature of $1315^{\circ} \mathrm{C}$, and spreading rate of $12 \mathrm{~mm} \mathrm{yr}^{-1}$ unless specified otherwise. The ages between profiles have been calculated according to the LaLOC location (Fig. S2). Panel (a) has a hot layer of $200^{\circ} \mathrm{C}$ and an initial lithosphere thickness of $125 \mathrm{~km}$, capable of matching values of AF1 - 4 over a $20 \mathrm{Myr}$ period. For panels (b) and (c) each wide-angle profile has been tested for different hot layer models and corresponding initial lithosphere thickness (Table 2). On the African margin, panel (b) shows matches of first ocean crust thicknesses over $2.5 \mathrm{Myr}$, much closer to the observed range of 1.0 Myr. For the South American margin, the models in panel (c) have a range of spreading velocities, where Segment 3a (for SA1) has a rate of $12 \mathrm{~mm} \mathrm{yr}^{-1}$, and Segment 1 (for SA2 and 3) has a rate of $18 \mathrm{~mm} \mathrm{yr}^{-1}$. Here the models match over a time of 7.7 Myr, relatively close to the observed time of 5.7 Myr. 

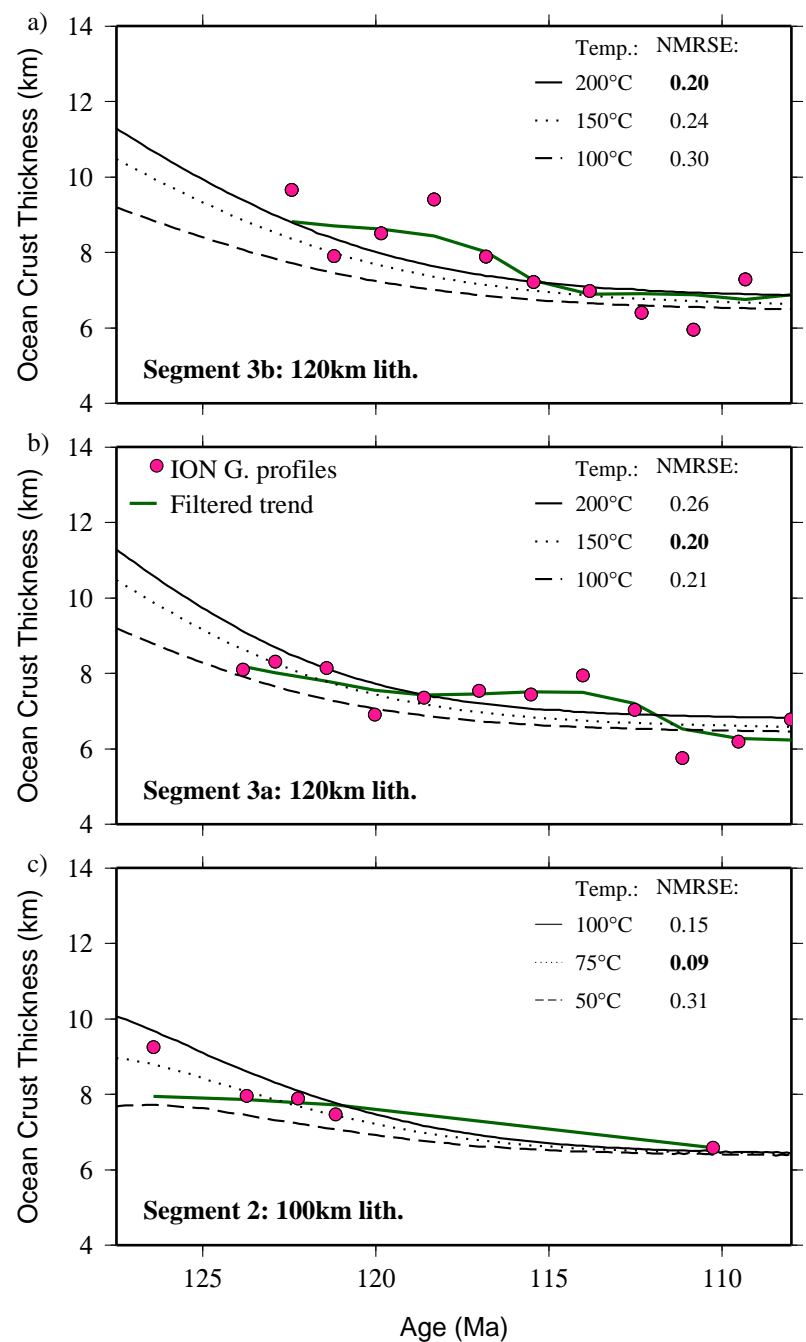

Figure 13: Model results per segment on the South American margin. Model asthenosphere temperature of $1315^{\circ} \mathrm{C}$, and spreading rate of $12 \mathrm{~mm} \mathrm{yr}^{-1}$. Each segment is tested for different hot layer models. The best match model trend was found by calculating a normal root mean square error (NMRSE) for each of the 1.5 Myr binned observation points (pink dots) with the preferred result in bold. Results for Segments 3b (a), 3a (b) and 2 (c) have hot layers with temperatures of $200{ }^{\circ} \mathrm{C}, 150{ }^{\circ} \mathrm{C}$ and $75^{\circ} \mathrm{C}$ respectively. 


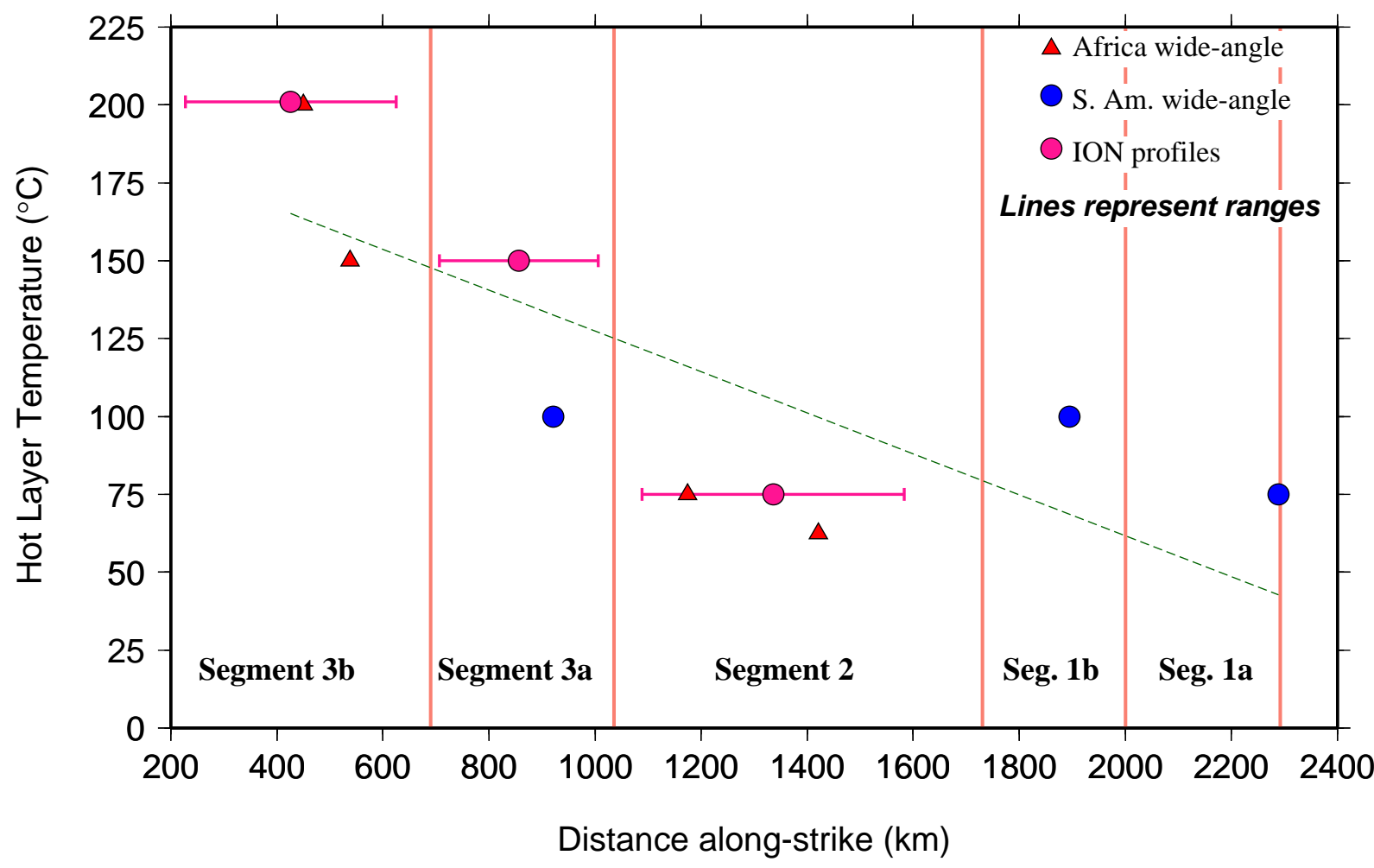

Figure 14: Hot layer temperature vs. distance along-strike. Results for the wide-angle profiles shown in Fig. 12 are given as symbols. Results for the long MCS profiles shown in Fig. 13 are marked as pink circles with horizontal bars marking distribution of the profiles. There is an overall reduction of $\sim 40^{\circ} \mathrm{C}$ per $500 \mathrm{~km}$. 

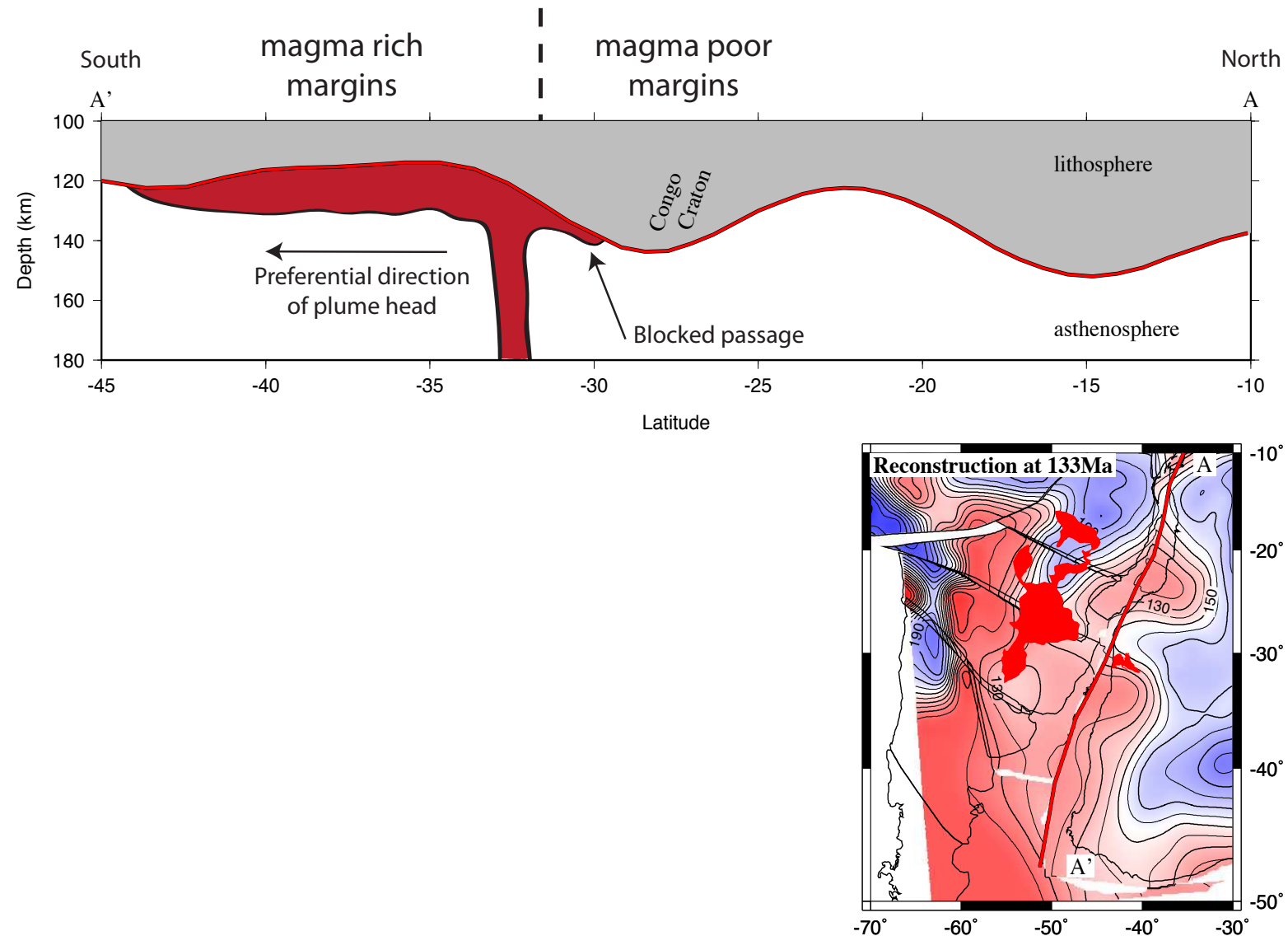

Figure 15: Cartoon of a possible explanation for the magma-rich and magma-poor passive margins in the South Atlantic. Lithosphere thickness (from Priestley and McKenzie, 2006) at $133 \mathrm{Ma}$, with the latter covering the whole area. The transect is shown on map, and approximate locations of major features are marked. 
Table 1: Crustal thickness measurements at the LaLOC for all seismic sections used in this study. The sections themselves are reproduced in the supplement (Fig. S2-S7). Distance along-strike refers to the location of the LaLOC relative to the commencement of the Rio Grande Rise and Walvis Ridge, marked with ' + ' in Fig. 1. Uncertainties in the measured oceanic crustal thickness are found in Table S1.

\begin{tabular}{|c|c|c|c|c|c|c|}
\hline Profile Name & Reference & Long. & Lat. & $\begin{array}{c}\text { Distance along- } \\
\text { strike }(\mathrm{km})\end{array}$ & $\begin{array}{l}\text { Thickness } \\
\text { (TWTT s) }\end{array}$ & $\begin{array}{c}\text { Thickness } \\
(\mathrm{km})\end{array}$ \\
\hline AF 1 & Bauer et al., 2000 & 11.9 & -23.8 & 450 & $\mathrm{n} / \mathrm{a}$ & 11.7 \\
\hline AF2 & Bauer et al., 2000 & 12.1 & -24.6 & 538 & $\mathrm{n} / \mathrm{a}$ & 8.2 \\
\hline AF3 & Schinkel et al., 2006 & 13.8 & -30.1 & 1174 & $\mathrm{n} / \mathrm{a}$ & 7.2 \\
\hline $\mathrm{AF} 4$ & Hirsch et al., 2009 & 14.6 & -32.3 & 1422 & $\mathrm{n} / \mathrm{a}$ & 7 \\
\hline $\mathrm{SA} 1$ & Becker et al., 2014 & -51.6 & -35.4 & 922 & $\mathrm{n} / \mathrm{a}$ & 8.2 \\
\hline $\mathrm{SA} 2$ & Schnabel et al., 2008 & -56.6 & -43.5 & 1895 & $\mathrm{n} / \mathrm{a}$ & 7.8 \\
\hline $\mathrm{SA} 3$ & Becker et al., 2014 & -58.1 & -47.2 & 2288 & $\mathrm{n} / \mathrm{a}$ & 6.9 \\
\hline BGR87-01 & Hinz et al., 1999 & -52.6 & -37.9 & 1197 & 2.26 & 7.6 \\
\hline BGR98-18 & Franke et al., 2010 & -55.8 & -43.4 & 1844 & 2.23 & 7.4 \\
\hline BGR98-07 & Franke et al., 2010 & -55.9 & -43.8 & 1884 & 2.30 & 7.7 \\
\hline BGR98-20 & Franke et al., 2010 & -56.5 & -44.0 & 1931 & 2.27 & 7.6 \\
\hline BGR98-01 & Franke et al., 2007 & -53.6 & -40.0 & 1439 & 2.16 & 7.2 \\
\hline BGR98-41 & Franke et al., 2007 & -55.2 & -42.1 & 1697 & 2.12 & 7.1 \\
\hline BGR98-15 & Franke et al., 2007 & -55.6 & -42.7 & 1774 & 2.06 & 6.9 \\
\hline BGR98-05 & Franke et al., 2007 & -55.7 & -43.3 & 1829 & 2.32 & 7.8 \\
\hline BGR98-22 & Franke et al., 2007 & -56.8 & -44.4 & 1982 & 2.05 & 6.9 \\
\hline BGR04-08/13 & Franke et al., 2007 & -56.7 & -47.5 & 2263 & 1.80 & 6.0 \\
\hline Profile 300 & Winterbourne et al., 2014 & -49.6 & -32.6 & 593 & $\mathrm{n} / \mathrm{a}$ & 7.7 \\
\hline Profile 231 & Winterbourne et al., 2014 & -53.3 & -39.6 & 1380 & $\mathrm{n} / \mathrm{a}$ & 5.9 \\
\hline Profile 233 & Winterbourne et al., 2014 & -54.8 & -41.0 & 1578 & $\mathrm{n} / \mathrm{a}$ & 8.4 \\
\hline Profile 230 & Winterbourne et al., 2014 & -54.5 & -41.3 & 1595 & $\mathrm{n} / \mathrm{a}$ & 6.8 \\
\hline Profile 229 & Winterbourne et al., 2014 & -57.2 & -46.7 & 2210 & $\mathrm{n} / \mathrm{a}$ & 5.1 \\
\hline Profile 232 & Winterbourne et al., 2014 & -57.3 & -47.3 & 2261 & $\mathrm{n} / \mathrm{a}$ & 5.1 \\
\hline PS1-0090 & ION Geophysical & -46.5 & -31.3 & 262 & 2.94 & 9.9 \\
\hline PS1-0070 & ION Geophysical & -48.2 & -31.5 & 405 & 2.87 & 9.6 \\
\hline PS1-0060 & ION Geophysical & -48.8 & -32.0 & 488 & 3.35 & 11.2 \\
\hline PS1-0040 & ION Geophysical & -49.7 & -32.9 & 609 & 3.24 & 10.9 \\
\hline PS1-0030 & ION Geophysical & -48.9 & -34.6 & 695 & 2.17 & 7.3 \\
\hline PS1-0010 & ION Geophysical & -50.7 & -35.0 & 828 & 2.55 & 8.5 \\
\hline UY1-4700 & ION Geophysical & -51.2 & -35.6 & 911 & 2.18 & 7.3 \\
\hline UY1-4500 & ION Geophysical & -51.6 & -36.3 & 992 & 2.39 & 8.0 \\
\hline UY1-4300 & ION Geophysical & -51.9 & -37.1 & 1076 & 2.36 & 7.9 \\
\hline UY1-4000 & ION Geophysical & -52.4 & -37.9 & 1176 & 2.25 & 7.5 \\
\hline AR1-3800 & ION Geophysical & -52.8 & -38.2 & 1220 & 2.54 & 8.5 \\
\hline AR1-3500 & ION Geophysical & -53.5 & -39.5 & 1369 & 2.73 & 9.1 \\
\hline AR1-3000 & ION Geophysical & -54.4 & -41.4 & 1583 & 1.93 & 6.4 \\
\hline AR1-2600 & ION Geophysical & -55.9 & -42.5 & 1760 & 2.89 & 9.7 \\
\hline
\end{tabular}


Table 2: Assigned model parameters: lithosphere thickness and spreading rates per segment. Opening ages are assumed by sub-plate from Moulin et al. (2010). M7, M4, M2 and M0 are dated 127.23 Ma, 126.57 Ma, 124.05 Ma and 120.6 Ma respectively (Gee and Kent, 2007). Seismic tomography models from Fishwick and Bastow (2011) and Priestley and McKenzie (2006) grids (Fig. S10). Spreading rates are from Heine et al. (2013).

\begin{tabular}{|c|c|c|c|c|c|}
\hline & $\begin{array}{c}\text { Opening } \\
\text { Ages }\end{array}$ & \multicolumn{3}{|c|}{ Lithosphere thickness $(\mathrm{km})$} & Spreading Rates \\
Segment & & $\begin{array}{c}\text { African margin } \\
\text { (Fishwick) }\end{array}$ & $\begin{array}{c}\text { African margin } \\
\text { (Priestley) }\end{array}$ & $\begin{array}{c}\text { S. American margin } \\
\text { (Priestley) }\end{array}$ & $\left(\mathrm{mm} \mathrm{yr}^{-1}\right)$ \\
\hline 3b & M2-M0 & $135-140$ & $105-110$ & 125 & 12 \\
\hline 3a & M2-M0 & $125-130$ & $100-105$ & 125 & 12 \\
\hline 1b & M4-M2 & $130-135$ & $95-100$ & $100-110$ & 12 \\
\hline 1a & pre-M7 & $130-135$ & $95-100$ & $110-115$ & 18 \\
\hline
\end{tabular}


814

\subsection{Seaward Dipping Reflector distributions}

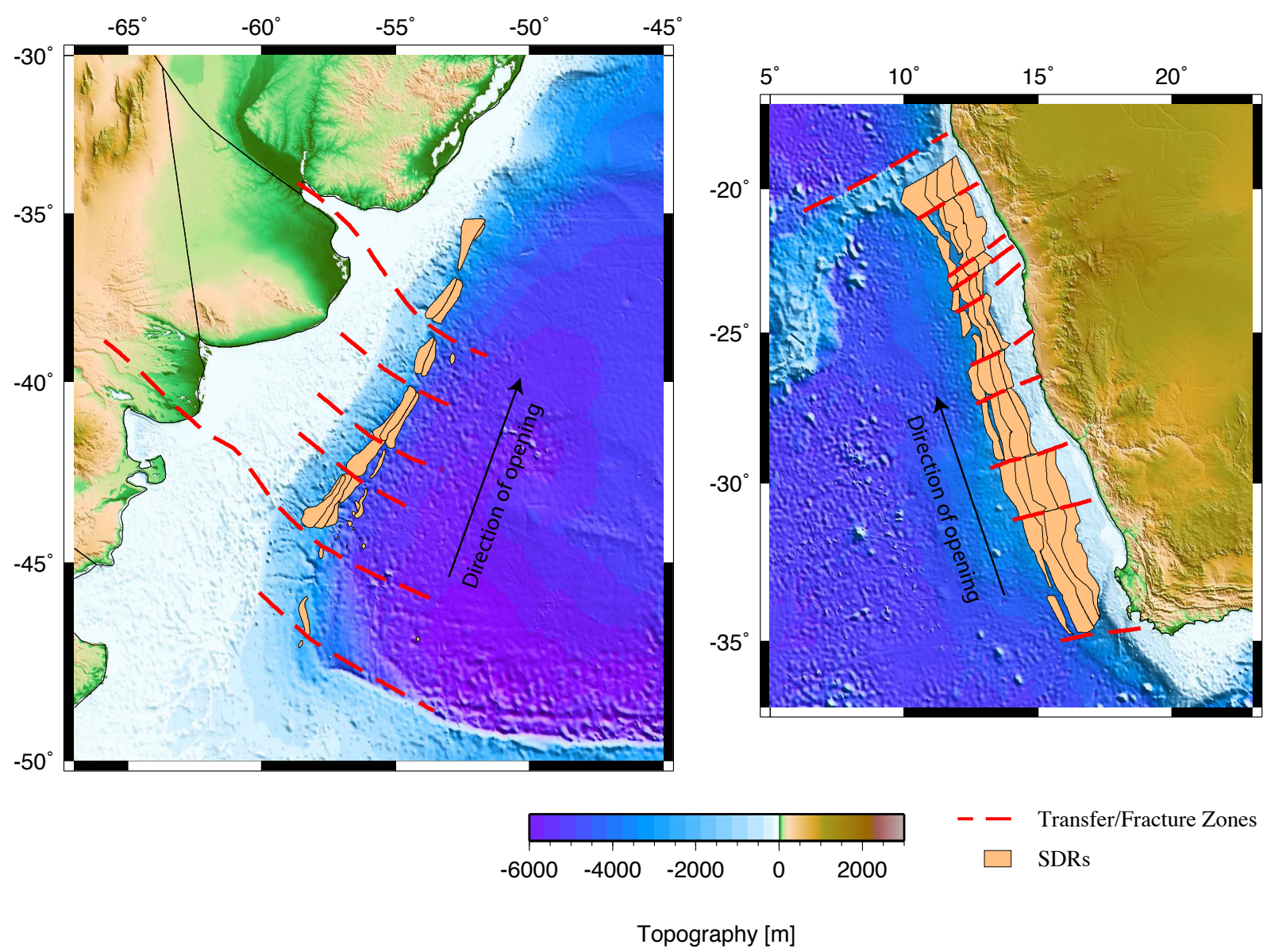

Figure S1: SDRs and segment boundaries from Franke et al. (2007) and Koopmann et al. (2014b). There is a general widening of SDRs approaching the segment boundaries, attributed to increased decompression melting. 

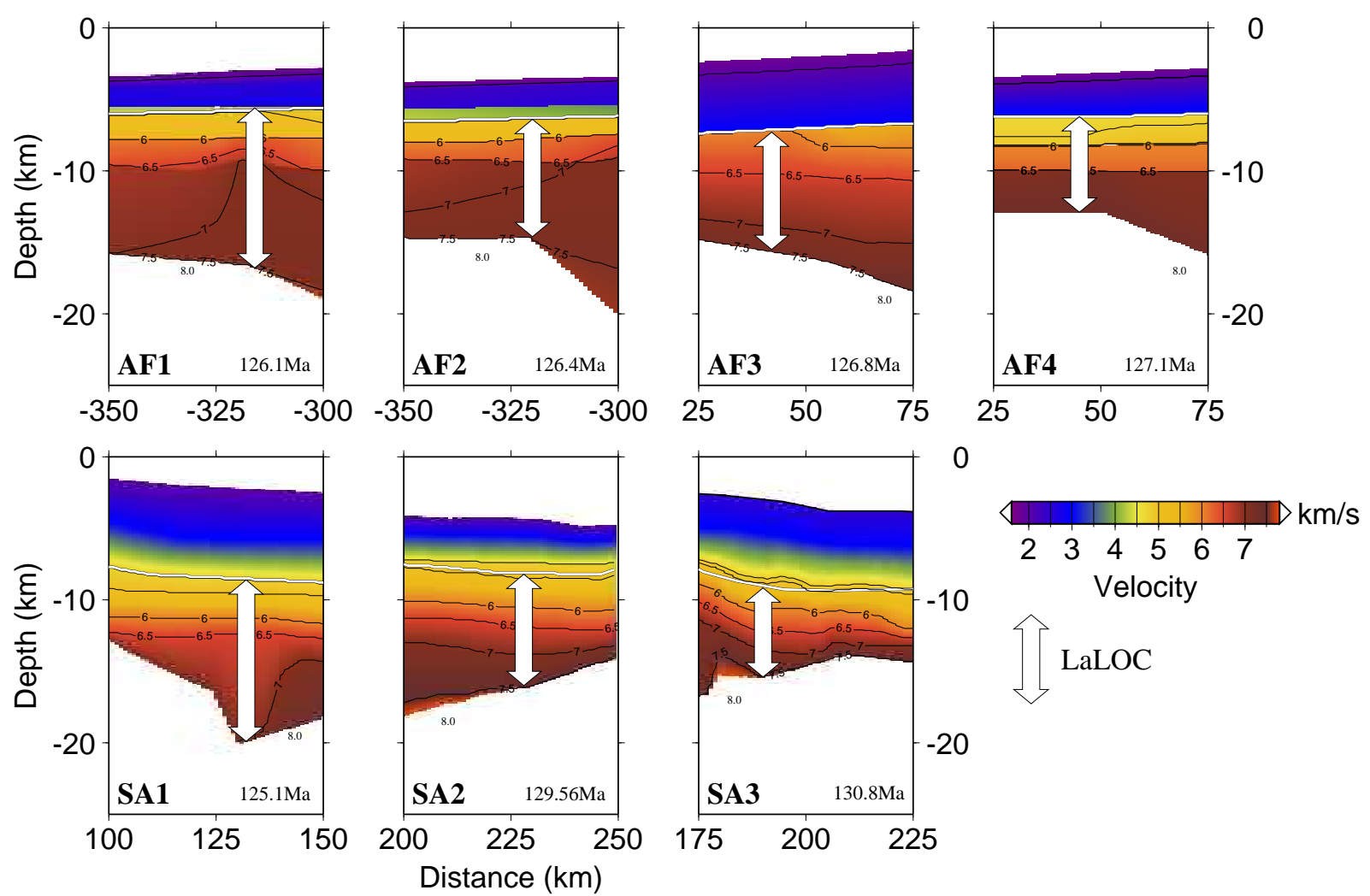

LaLOC

Figure S2: Ocean crust measurement points at the LaLOC for wide-angle seismic profiles. AF1 \& 2, 3 and 4 from Bauer et al. (2000), Schinkel (2006) and Hirsch et al. (2009) respectively, SA1 \& 2 and SA3 from Becker et al. (2014) and Schnabel et al. (2008) respectively. Ages are determined from an age grid using the Gee and Kent (2007) time scale and Moulin et al. (2010) magnetic isochrons. 

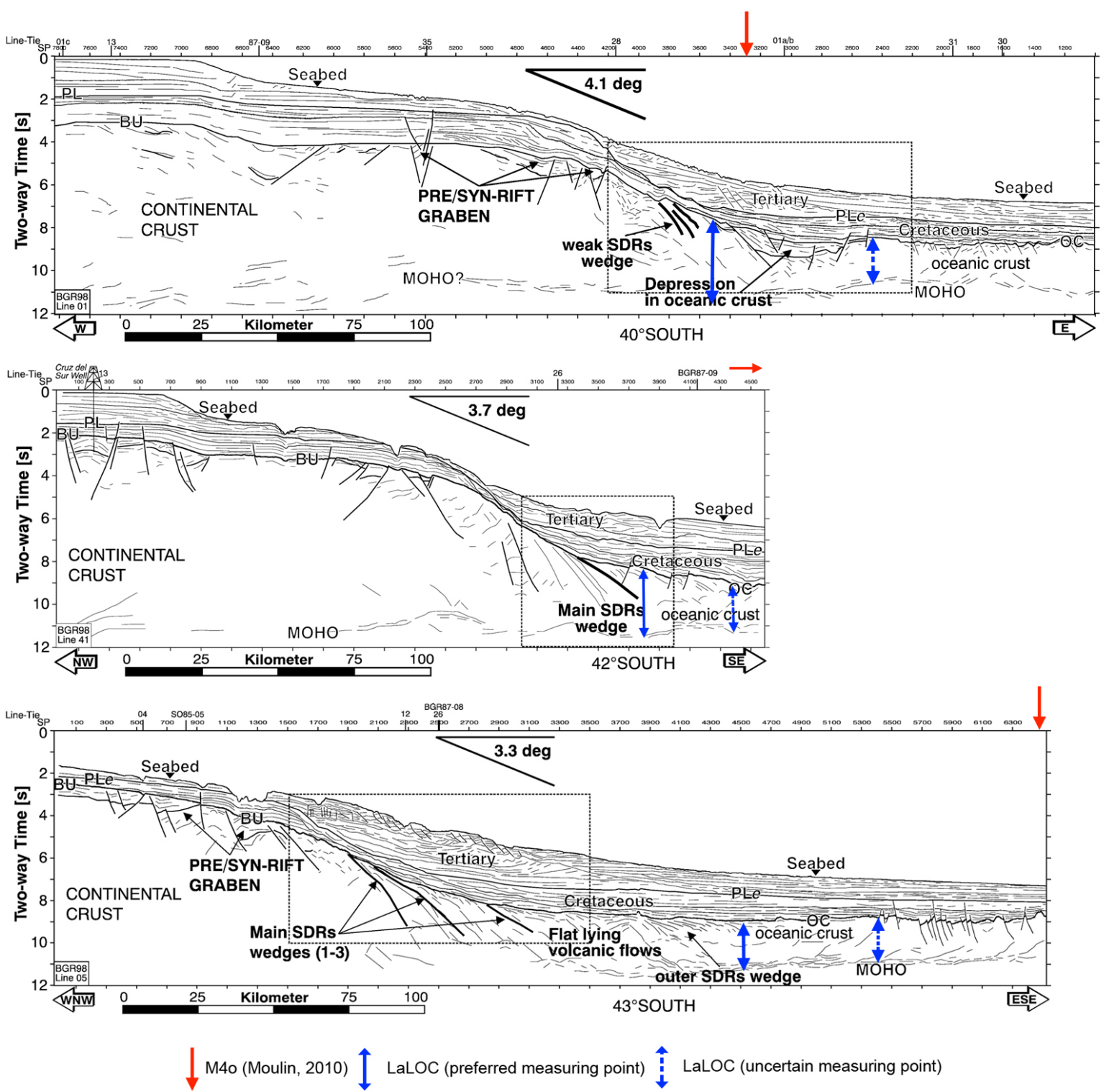

Figure S3: Crustal thickness measurement at the LaLOC locations for BGR98-01, 41 and 05 (line locations Fig. S8). Modified from Franke et al. (2007). 


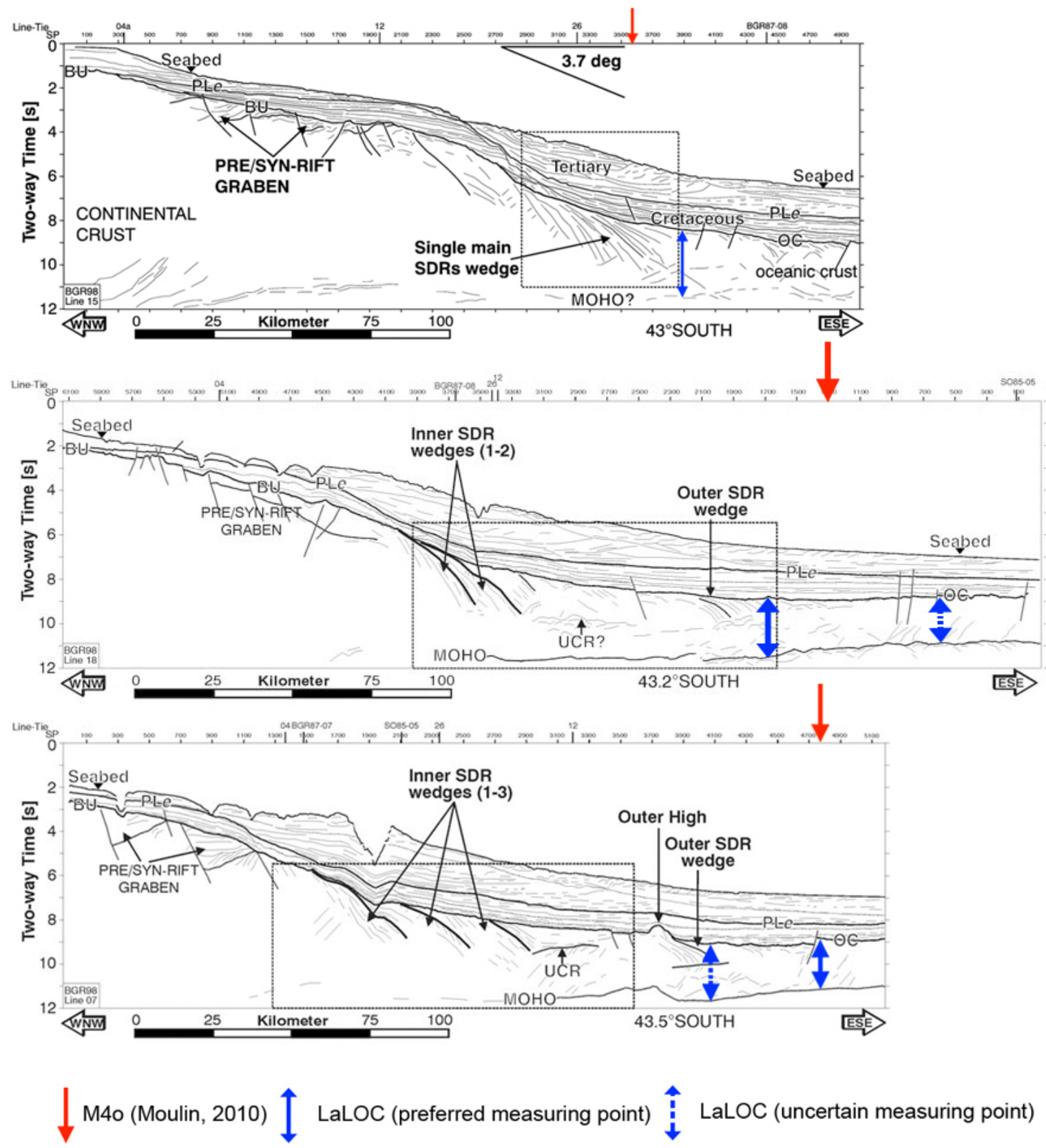

Figure S4: Crustal thickness measurement at the LaLOC locations for BGR98-15, 18 and 07 (line locations Fig. S8). Modified from Franke et al. (2007, 2010). 

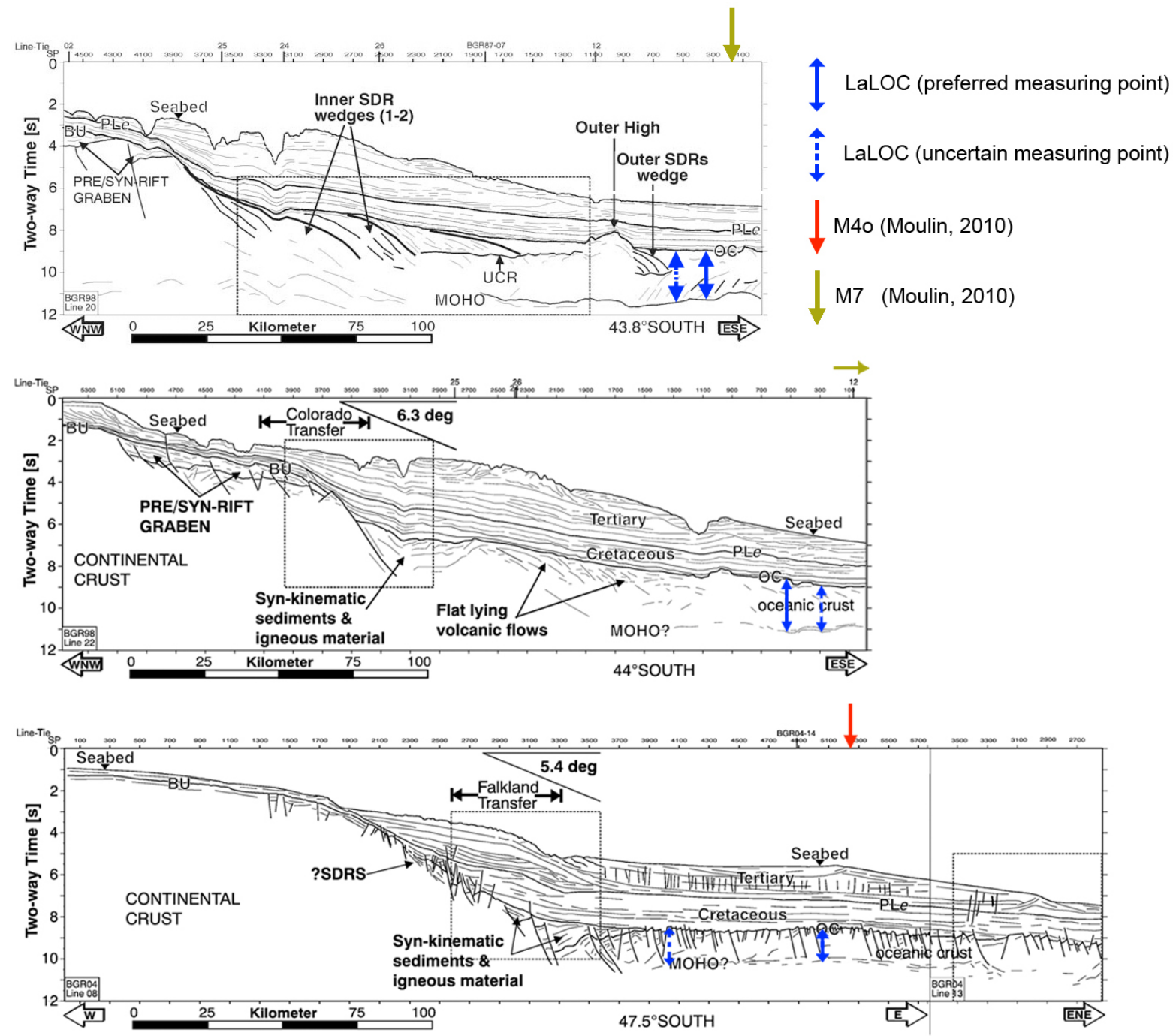

Figure S5: Crustal thickness measurement at the LaLOC locations for BGR98-20, 22 and 08/13 (line locations Fig. S8). Modified from Franke et al. (2007, 2010). 


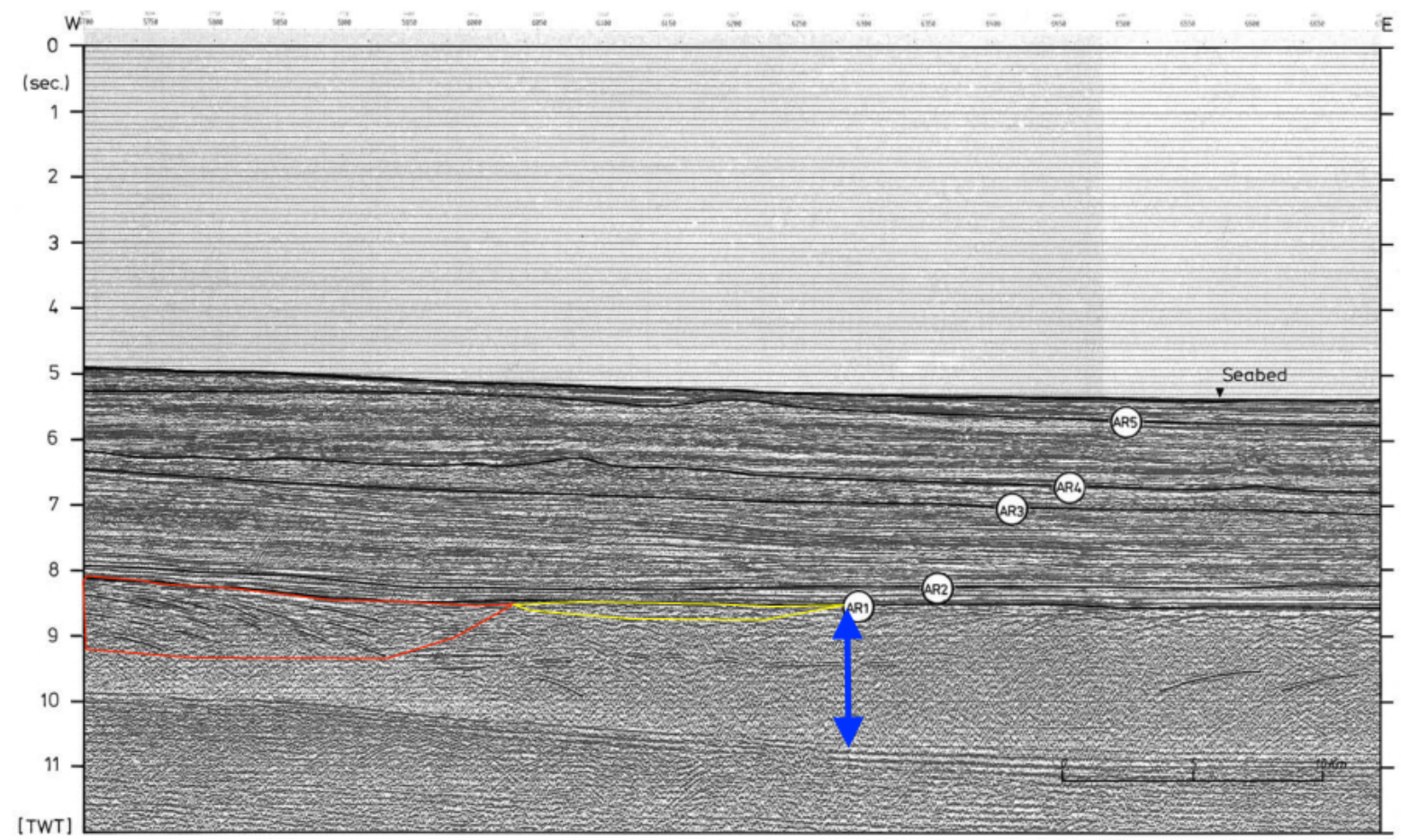

Figure S6: Crustal thickness measurement at the LaLOC location for BGR87-01B (line location Fig. S8), modified from Hinz et al. (1999). Red and yellow packages represent SDRs, blue arrow represent location of LaLOC.

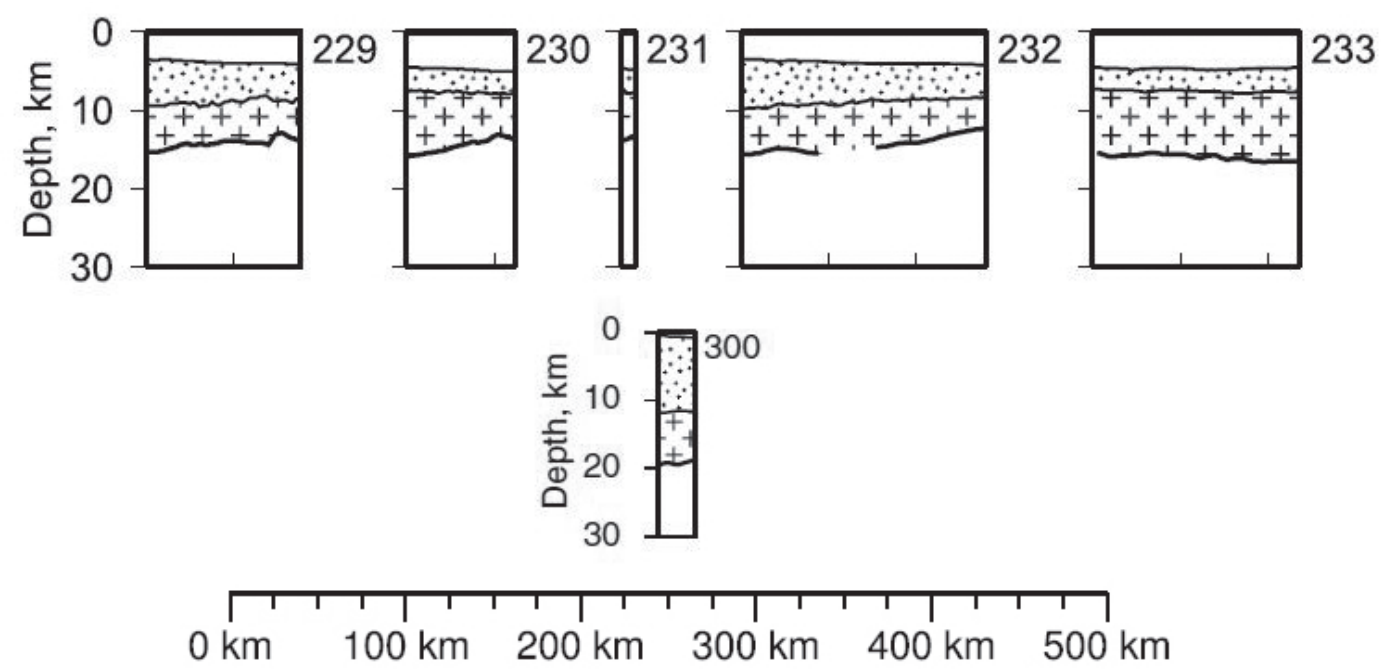

Figure S7: Crustal thickness measurement at the LaLOC locations for Winterbourne et al. (2014) data. Ocean crust depicted by '+', and sediment by dots. 


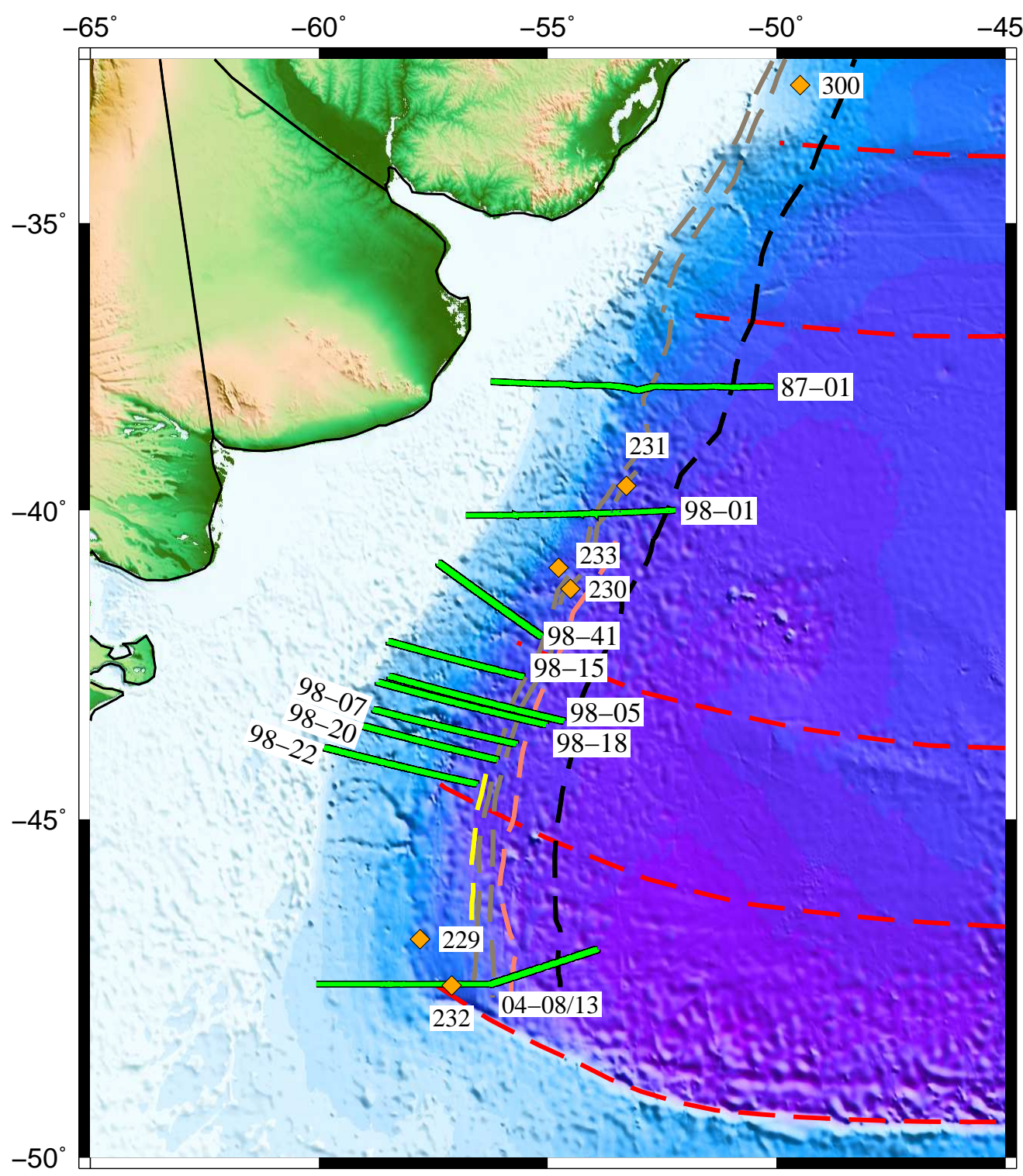

Segment 3a

Segment 2

Segment 1b

Segment 1a

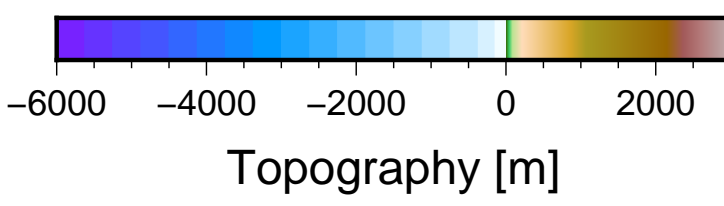

- - Segment Boundaries

- BGR lines

$\begin{array}{ll}\text { M0 } & = \\ \text { M2 } & \text { M4 } \\ & \text { Published Points }\end{array}$

Figure S8: Map of the BGR MCS line locations for Fig. S3-S6 and published points from Winterbourne et al. (2014) for Fig. S7. Topography and bathymetry is from ETOP01 Armante (2009). The sea floor spreading magnetic anomalies (M0, M2, M4 and M7) and plate boundaries (thin black lines) are from Moulin et al. (2010). 


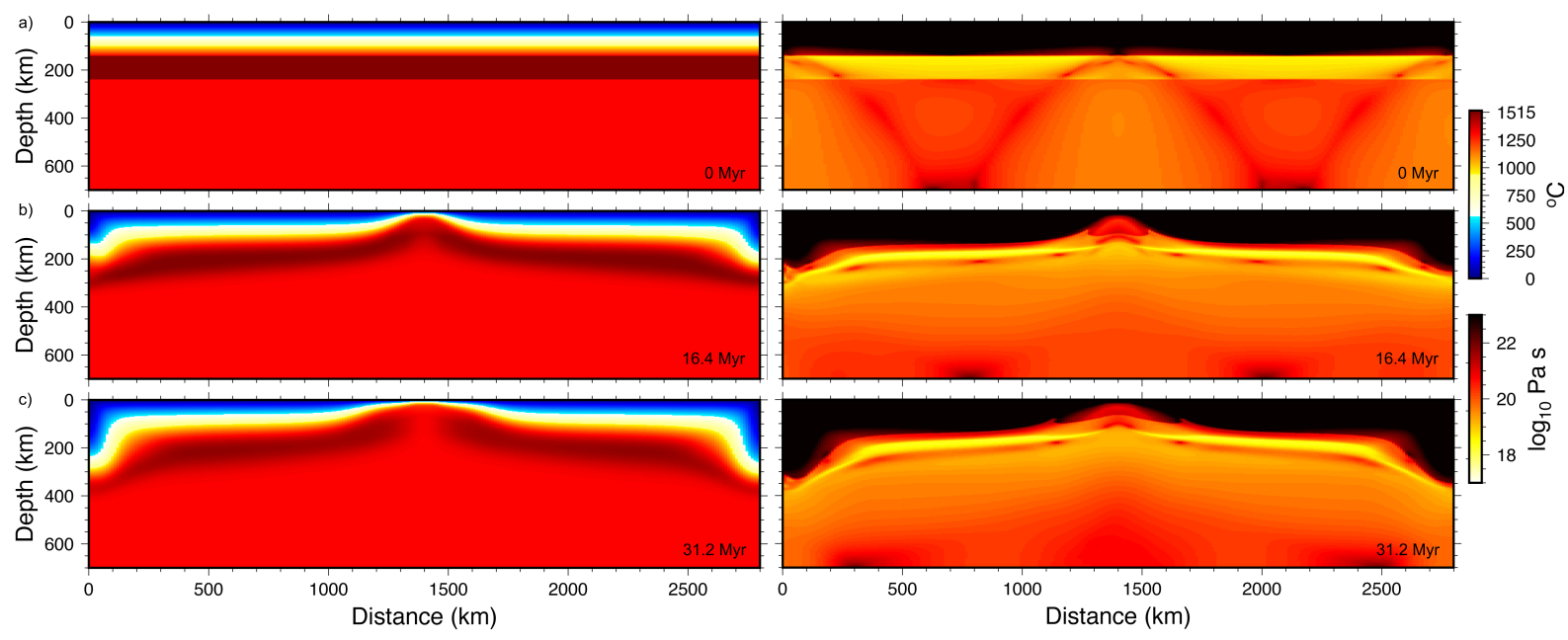

Figure S9: A comparison of the model at different timesteps in terms of evolving temperature and viscosity. There is a $200^{\circ} \mathrm{C}$ hot layer, with a lithosphere thickness of $140 \mathrm{~km}$ and spreading rate of $12 \mathrm{~mm} \mathrm{yr}^{-1}$. (a) Represents the model at $0 \mathrm{Myr}$, similar to Fig. 5. (b) Represents the model at $16.4 \mathrm{Myr}$, during the syn-rift stage and approximately matching peak melt thickness, and (c) represents the model at 31.2 Myr, in the post-rift phase. In parts (b) and (c) the zone of partial melting is observed at the centre top of the model. The reflective boundaries can be seen in (b) and (c), and are considered far enough not to affect melt thickness production. 
Table S1: Crustal thickness measurements, with maximum and minimum ranges at the LaLOC for all seismic sections used in this study. These ranges provide the error bars shown in Fig. 8. The sections themselves are reproduced in Fig. S2-S7. The measurements reported in Winterbourne et al. (2014) are from proprietary data. Distance along-strike refers to the location of the LaLOC relative to the commencement of the Rio Grande Rise and Walvis Ridge, marked with '+' in Fig. 1.

\begin{tabular}{|c|c|c|c|c|c|}
\hline Profile Name & Reference & $\begin{array}{c}\text { Distance } \\
\text { along-strike }(\mathrm{km})\end{array}$ & $\begin{array}{l}\text { Thickness } \\
(\mathrm{km})\end{array}$ & $\begin{array}{l}\text { Thickness } \\
\text { max. }(\mathrm{km})\end{array}$ & $\begin{array}{l}\text { Thickness } \\
\text { min. }(\mathrm{km})\end{array}$ \\
\hline AF $1 /$ Mamba 1 & Bauer et al., 2000 & 450 & 11.7 & 12.9 & 11.2 \\
\hline $\mathrm{AF} 2 / \mathrm{Mamba} 2$ & Bauer et al., 2000 & 538 & 8.2 & 10.9 & 8 \\
\hline AF3/Orange & Schinkel et al., 2006 & 1174 & 7.2 & 8.2 & 6.2 \\
\hline AF4/Springbok & Hirsch et al., 2009 & 1422 & 7 & 11.7 & 6.7 \\
\hline SA1/BGR04-REFR1 & Becker et al., 2014 & 922 & 8.2 & 8.2 & 7.9 \\
\hline SA2/BGR98-REFR2 & Schnabel et al., 2008 & 1895 & 7.8 & 8.7 & 6.2 \\
\hline SA3/BGR98-REFR2 & Becker et al., 2014 & 2288 & 6.9 & 6.9 & 3.8 \\
\hline BGR87-01B & Hinz et al., 1999 & 1165 & 7.6 & 7.9 & 7.3 \\
\hline BGR98-18 & Franke et al., 2010 & 1850 & 7.4 & 7.7 & 7.1 \\
\hline BGR98-07 & Franke et al., 2010 & 1894 & 7.7 & 8.0 & 7.4 \\
\hline BGR98-20 & Franke et al., 2010 & 1925 & 7.6 & 7.9 & 7.3 \\
\hline BGR98-41 & Franke et al., 2007 & 1681 & 7.1 & 7.4 & 6.8 \\
\hline BGR98-05 & Franke et al., 2007 & 1790 & 7.8 & 8.1 & 7.5 \\
\hline BGR98-15 & Franke et al., 2007 & 1804 & 6.9 & 7.2 & 6.6 \\
\hline BGR98-22 & Franke et al., 2007 & 1981 & 6.9 & 7.2 & 6.6 \\
\hline BGR04-08/13 & Franke et al., 2007 & 2258 & 6 & 6.3 & 5.7 \\
\hline Profile 300 & Winterbourne et al., 2014 & 593 & 7.7 & 8.0 & 7.4 \\
\hline Profile 231 & Winterbourne et al., 2014 & 1380 & 5.9 & 6.2 & 5.6 \\
\hline Profile 233 & Winterbourne et al., 2014 & 1578 & 8.4 & 8.8 & 8.0 \\
\hline Profile 230 & Winterbourne et al., 2014 & 1595 & 6.8 & 7.1 & 6.5 \\
\hline Profile 229 & Winterbourne et al., 2014 & 2210 & 5.1 & 5.3 & 4.9 \\
\hline Profile 232 & Winterbourne et al., 2014 & 2261 & 5.1 & 5.3 & 4.9 \\
\hline PS1-0090 & ION Geophysical & 262 & 9.9 & 10.3 & 9.5 \\
\hline PS1-0070 & ION Geophysical & 405 & 9.6 & 10.0 & 9.2 \\
\hline PS1-0060 & ION Geophysical & 488 & 11.2 & 11.7 & 10.7 \\
\hline PS1-0040 & ION Geophysical & 609 & 10.9 & 11.4 & 10.4 \\
\hline PS1-0030 & ION Geophysical & 695 & 7.3 & 7.6 & 7.0 \\
\hline PS1-0010 & ION Geophysical & 828 & 8.5 & 8.9 & 8.1 \\
\hline UY1-4700 & ION Geophysical & 911 & 7.3 & 7.6 & 7.0 \\
\hline UY1-4500 & ION Geophysical & 992 & 8 & 8.4 & 7.6 \\
\hline UY1-4300 & ION Geophysical & 1076 & 7.9 & 8.3 & 7.5 \\
\hline UY1-4000 & ION Geophysical & 1176 & 7.5 & 7.8 & 7.2 \\
\hline AR $1-3800$ & ION Geophysical & 1220 & 8.5 & 8.9 & 8.1 \\
\hline AR1-3500 & ION Geophysical & 1369 & 9.1 & 9.5 & 8.7 \\
\hline AR $1-3000$ & ION Geophysical & 1583 & 6.4 & 6.7 & 6.1 \\
\hline AR $1-2600$ & ION Geophysical & 1760 & 9.7 & 10.1 & 9.3 \\
\hline
\end{tabular}



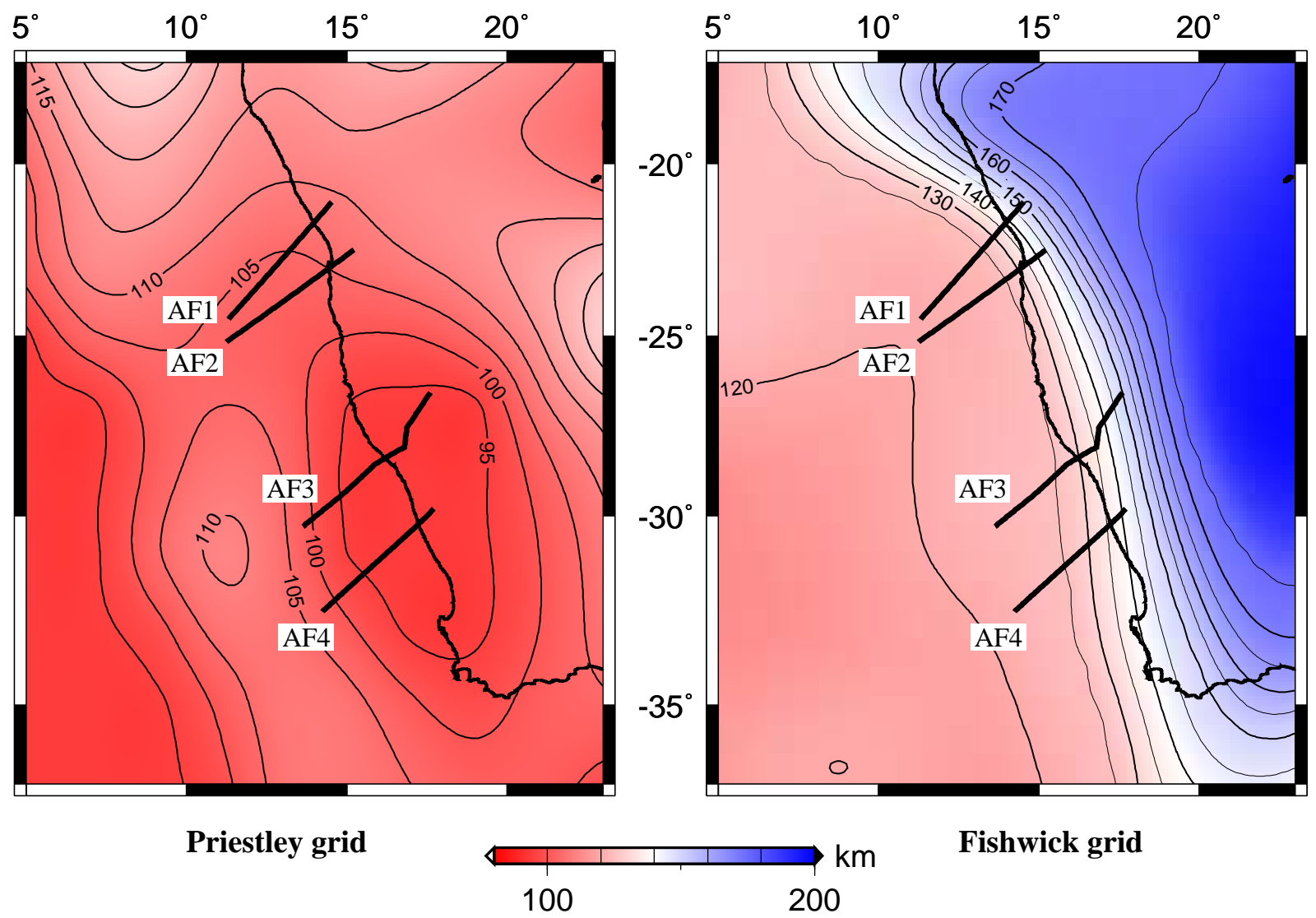

Fishwick grid

Thickness

Figure S10: Comparison of two seismic tomography models of lithospheric thickness of South West Africa used in the study from Priestley and McKenzie (2006) and Fishwick and Bastow (2011). Labelled lines show the location of the wide-angle profiles used. 

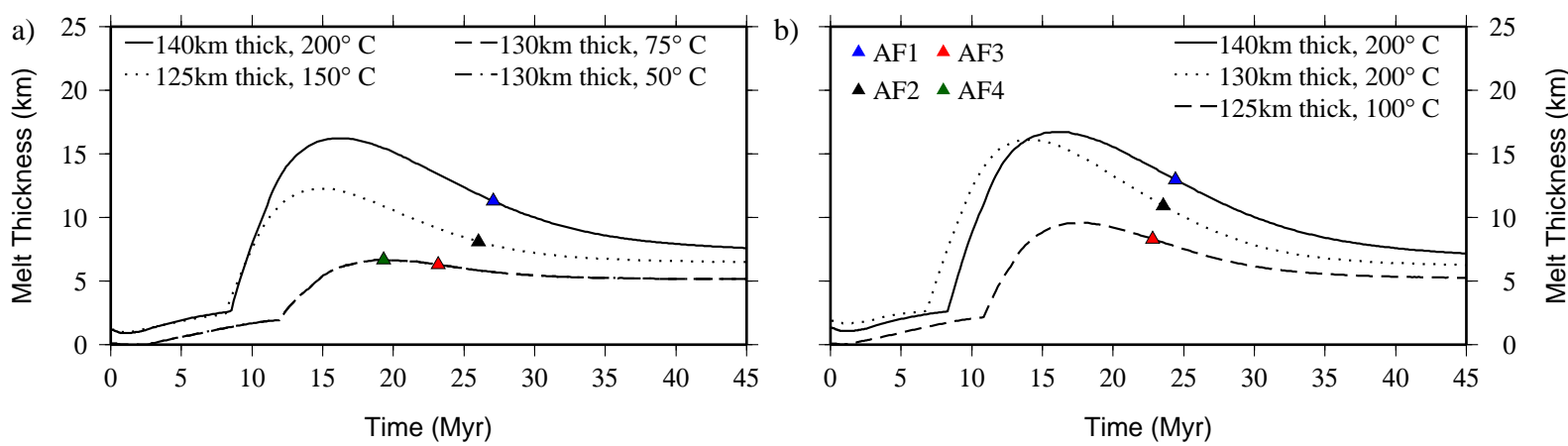

Figure S11: Models run with asthenosphere temperature of $1315^{\circ} \mathrm{C}$ and spreading rate of $12 \mathrm{~mm} \mathrm{yr}^{-1}$ for maximum and minimum ranges of the African wide-angle profiles. Panel (a) uses the minimum error range of initial ocean crustal thicknesses, however this results in the same hot layer temperature matches as in Fig. 12a. Panel (b) uses the maximum error range of initial ocean crustal thickness. AF4 is not included here due to its larger error range. Although hotter layers are required for AF2 and AF3, we still see a decrease in temperature along-strike. 
Table A1: Paremeters used for 2D-modelling.

\begin{tabular}{|c|c|c|}
\hline Variable & Definition & Value \\
\hline$A$ & rheological parameter & \\
\hline$c_{p}$ & specific heat capacity, $\mathrm{J} \mathrm{kg}^{-1} \mathrm{~K}^{-1}$ & 1200 \\
\hline$d$ & reference length, km & 700 \\
\hline$g$ & acceleration of gravity, $\mathrm{ms}^{-2}$ & 9.8 \\
\hline$E$ & activation energy, $\mathrm{J} \mathrm{mol}^{-1}$ & $530 \times 10^{3}$ \\
\hline$F$ & melt fraction & \\
\hline$h_{c}$ & crustal thickness, $\mathrm{km}$ & \\
\hline$L$ & latent heat upon melting, $\mathrm{J} \mathrm{mol}^{-1}$ & \\
\hline$\dot{m}$ & dimensionless melt production rate & \\
\hline$n$ & stress exponent & 3 \\
\hline$p$ & pressure, $\mathrm{Pa}$ & \\
\hline$R$ & gas constant, $\mathrm{J} \mathrm{K}^{-1} \mathrm{~mol}^{-1}$ & 8.314 \\
\hline$R a$ & Rayleigh number & $4.877 \times 10^{5}$ \\
\hline$\Delta \mathrm{S}$ & change in entropy upon melting, $\mathrm{J} \mathrm{kg}^{-1} \mathrm{~K}^{-1}$ & 400 \\
\hline$T$ & mantle temperature, $\mathrm{K}$ & \\
\hline$T_{d}$ & super-adiabatic temperature drop, $\mathrm{K}$ & \\
\hline$T_{m}$ & mantle reference temperature & K \\
\hline$T_{s}$ & wet or dry solidus temperature, $\mathrm{K}$ & \\
\hline$T_{s 0}$ & dry solidus surface temperature & $\mathrm{K}$ \\
\hline$u$ & mantle creep, $\mathrm{ms}^{-1}$ & \\
\hline V & activation volume, $\mathrm{J} \mathrm{mol}^{-1}$ & $5 \times 10^{-6}$ \\
\hline$X$ & concentration of perfectly compatible trace element & \\
\hline$x$ & displacement, $\mathrm{km}$ & \\
\hline$z$ & depth, $\mathrm{km}$ & \\
\hline$\alpha$ & coefficient of thermal expansion, $\mathrm{K}^{-1}$ & $3.3 \times 10^{-5}$ \\
\hline$\delta_{p}$ & density change due to temperature and melt generation & \\
\hline$\dot{\epsilon}$ & strain rate, $\mathrm{s}^{-1}$ & \\
\hline$\eta$ & viscosity, $\mathrm{Pas}$ & \\
\hline$\eta_{0}$ & reference viscosity, Pas & $10^{21}$ \\
\hline$\kappa$ & thermal diffusivity, $\mathrm{m}^{2} \mathrm{~s}^{-1}$ & $10^{-6}$ \\
\hline$\lambda_{i}$ & unit vector in vertical direction & \\
\hline$\phi$ & retained melt (porosity) & \\
\hline$\Delta \rho$ & density change due to temperature and melt generation, $\mathrm{kg} \mathrm{m}^{-3}$ & \\
\hline$\rho_{m}$ & mantle reference density, $\mathrm{kg} \mathrm{m}^{-3}$ & 3340 \\
\hline$\rho_{l}$ & melt density, $\mathrm{kg} \mathrm{m}^{-3}$ & 2800 \\
\hline$\rho_{r}$ & density of mantle at reference residue $X_{r}, \mathrm{~kg} \mathrm{~m}^{-3}$ & 3295 \\
\hline$\tau$ & deviatoric stress, $\mathrm{Pa}$ & \\
\hline$\chi_{\mathrm{H}_{2} \mathrm{O}}$ & viscosity increase due to dehydration & \\
\hline$\chi_{m}$ & viscosity decrease factor due to interstitial melt & \\
\hline
\end{tabular}




\section{A1.1. Equations of Conservation}

CitCom is a combined Stokes and energy equation solver, used for incompressible flow occurring over large viscosity contrasts (Moresi et al., 1996). The model assumes the mantle has a non-Newtonian rheology (Nielsen and Hopper, 2004). Equations are solved in 2D, using the Boussinesq approximation with the understanding that (1) density variations are sufficiently small that they only affect gravitational forces and (2) effect on mantle density due to mass transfer during melting is small (Cordery and Morgan, 1993). The dynamics of the system is solved by equations of thermal convection, the conservation of mass, momentum and energy (Eqs. 2-4)

$$
\begin{gathered}
\frac{\partial u_{i}}{\partial x_{i}}=0 \\
-\frac{\partial \tau_{i j}}{\partial x_{j}}+\frac{\partial p}{\partial x_{i}}=\Delta \rho g \lambda_{i} \\
\frac{\partial T}{\partial t}=-u_{i} \frac{\partial T}{\partial x_{i}}+\kappa \frac{\partial^{2} T}{\partial x_{j}^{2}}-\frac{L \dot{m}}{c_{p}}
\end{gathered}
$$

where $\mathrm{u}$ is the solid mantle creep, $\tau_{i j}$ is the deviatoric stress tensor, $\Delta \rho$ is the density change due to temperature and melt generation, $\lambda_{i}$ is the unit vector in the vertical direction, and $T$ is the mantle temperature. More details of the constants can be found in Table A1. $L$, the latent heat of melting, is calculated by

$$
L=T_{m} \Delta S
$$

where $T_{m}$ is the mantle reference and $\Delta S$ is the entropy change upon melting.

\section{A1.2. Decompression Melting}

The model considers the effect of mantle depletion and dehydration. This is done by considering $X$, the concentration of a perfectly compatible trace element (Scott, 1992), given as: 


$$
\frac{\partial X}{\partial t}+u_{i} \frac{\partial X}{\partial x_{i}}=\frac{X}{1-\phi} \dot{m}
$$

where $\phi$ is melt volume and $\dot{m}$ is melt production rate. When no melting has occurred, the concentration of $X=1$. The value of $\mathrm{X}$ is always positive throughout melting. By assuming batch melting for each time step, the melt fraction $F$ can be calculated (Scott, 1992) using,

$$
X(1-F)=1
$$

The conservation of energy (Eq. 4) and the continuity of the concentration of $X$ (Eq. 6) are linked by the melt production rate $\dot{m}$. Melt production rate $\dot{m}$ is dependent on the solidus, here defined as a function of depth and depletion of $X$, from Scott (1992) and Phipps Morgan (2001),

$$
T_{s}^{r e a l}=T_{s 0}+z\left(\frac{\partial T_{s}}{\partial z}\right)_{X}+\left(\frac{\partial T_{s}}{\partial X}\right)_{z}(X-1)
$$

where $T_{s 0}$ is the dry solidus temperature at the surface, where $z$ is 0 at the surface. By correcting for the adiabatic temperature change, $T_{s}^{\text {real }}$ can be converted to potential temperature,

$$
\left(\frac{\partial T}{\partial z}\right)_{s}=\frac{g \alpha T}{c_{p}}
$$

and the solidus for dry rock can be defined,

$$
T_{s}^{d r y}=T_{s 0}+z\left(\left(\frac{\partial T_{s}}{\partial z}\right)_{X}-\left(\frac{\partial T}{\partial z}\right)_{S}\right)+\left(\frac{\partial T_{S}}{\partial X}\right)_{z}(X-1)
$$

To acknowledge volatiles in a mantle affecting melting depth, we introduce a deeper wet solidus following Braun et al. (2000) where,

$$
T_{s}^{w e t}=T_{s}^{d r y}-\Delta T_{s} \frac{1.02-X}{\Delta X} .
$$


Wet melting is considered to occur until $2 \%$ of melt is produced. Once this point is reached, the mantle is devoid of mantle volatiles and the dry solidus (Eq. 10) is reached. To achieve this the melt productivity is lowered during wet melting. The melt production is further computed for each time step, using the positioning of the wet and dry solidus (Eqs. 10 and 11), calculated by

$$
\delta m=\frac{\delta t}{\frac{L}{c_{p}}+\frac{\partial T_{s}}{\partial \phi}}
$$

where $\mathrm{T}_{s}$ is the temperature of the wet or dry solidus, $c_{p}$ is the specific heat capacity, $\delta T=T-T_{s}$ and $\delta t$ is the model timestep size. The differential $\partial T_{s} / \partial \phi$ is different for the wet and dry melting regime (from Braun et al. (2000)), calculated for the dry regime by

$$
\frac{\partial T_{s}}{\partial \phi}=300 \frac{X}{1-\phi} .
$$

and the wet regime by

$$
\frac{\partial T_{s}}{\partial \phi}=1300 \frac{X}{1-\phi} .
$$

Following this, the melt production rate can be calculated by

$$
\dot{m}=\frac{\delta m}{\delta t},
$$

where $\delta t$ represents the advection time step. Following Ito et al. (1996), the crustal thickness $h_{c}$ can be calculated by weighing the degree of melting $(F)$ by melt production $(\dot{m})$,

$$
h_{c}=\frac{2}{u_{z}}\left(\frac{\rho_{m}}{\rho_{l}}\right) \iint_{m e l t} \dot{m} d x d z
$$

where for each timestep, there is the assumption that all melt generated erupts at the centre of extension. 
The main equations of flow (Eqs. 2, 3 and 4) are made non-dimensional by the following,

$$
x=d x^{\prime}, t=\frac{d^{2}}{\kappa} t^{\prime}, T=T_{d} T^{\prime}, \eta=\eta_{0} \eta^{\prime}
$$

where $d$ is the depth of the model space and $T_{d}$ is the super adiabatic temperature drop from the base of the model to the surface.

The Rayleigh number is defined as,

$$
R a=\frac{\alpha g \rho T_{d} d^{3}}{\kappa \eta_{0}}
$$

Where $\alpha$ is the coefficient of thermal expansion and $g$ is the acceleration due to gravity. The Rayleigh number defines the viscosity $\eta$, where

$$
\eta=A \chi_{H_{2} O} \chi_{m} \exp \left(\frac{E+p V}{n R T}\right) \dot{\epsilon}^{\frac{1-n}{n}}
$$

where $E$ is the activation energy, $p$ is the pressure, $V$ is the activation volume, $n$ is the stress exponent, $R$ is the gas constant and $\epsilon$ is the strain rate. $A$ is the rheological parameter, accounting for mantle strengthening due to the removal of volatiles $\left(\chi_{\mathrm{H}_{2} \mathrm{O}}\right)$ and the weakening of the mantle due to the presence of melt $\left(\chi_{m}\right)$. 


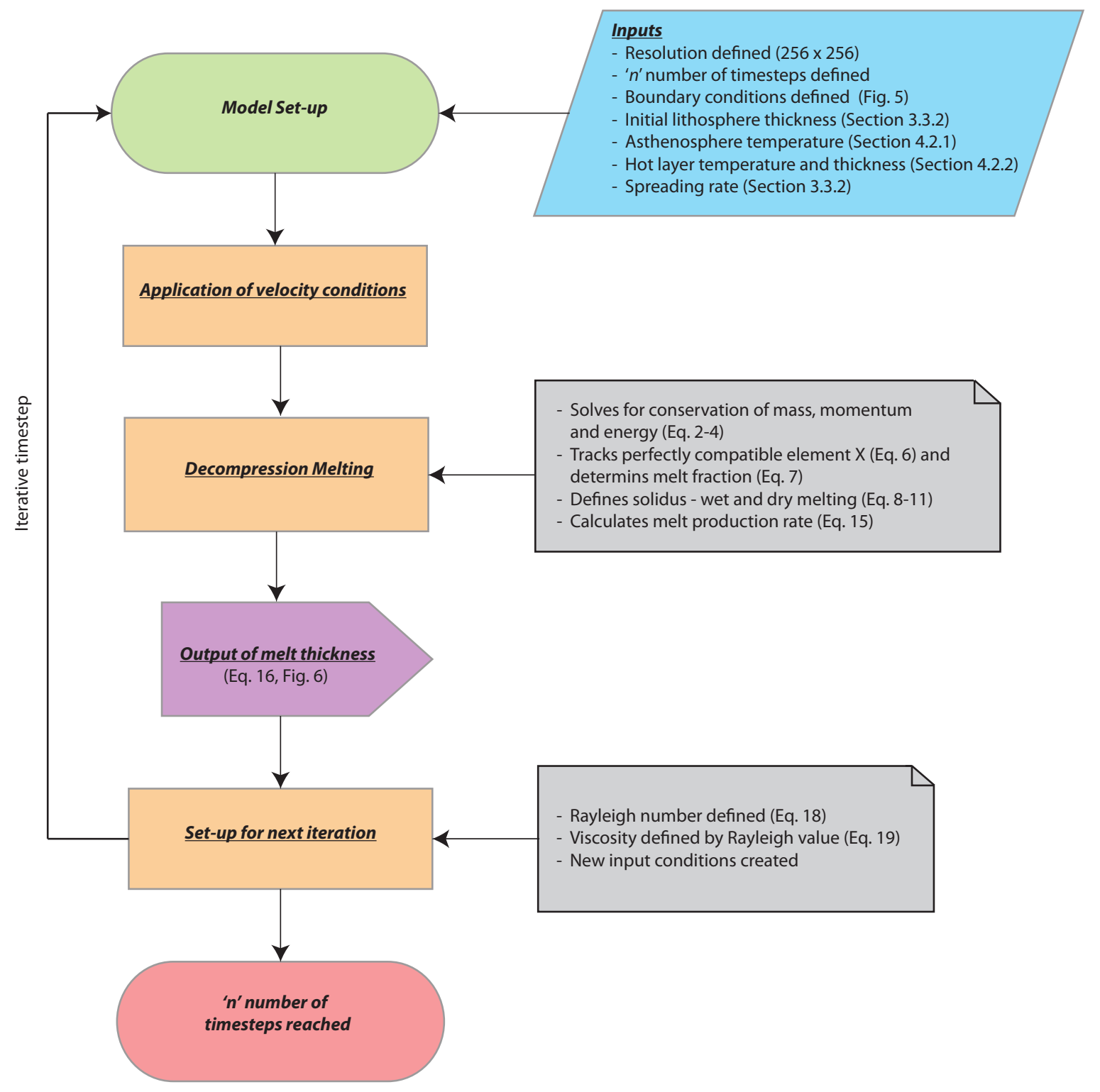

Figure S12: Basic flowchart for the CitCom model. The green box represents the start of the model, blue boxes represent inputs, orange boxes represent processes, grey boxes represent notes, the purple box represents the output and the red box represents the end of the model. 